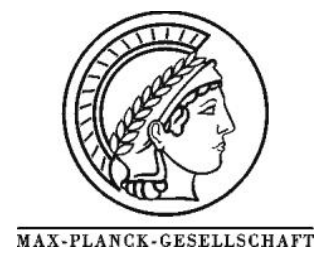

Carbon 47 (2009), 1779-1798

\title{
Analysis of the structure and chemical properties of some commercial carbon nanostructures
}

\author{
J.-P. Tessonnier, D. Rosenthal, T. W. Hansen, C. Hess ${ }^{\S}$, M. E. Schuster, R. Blume, F. Girgsdies, N. Pfän- \\ der, O. Timpe, D. S. Su,* R. Schlögl
}

Fritz-Haber-Institut der Max-Planck-Gesellschaft, Departement of Inorganic Chemistry, D-14195 Berlin, Germany

${ }^{\S}$ Present address: Eduard-Zintl-Institut für Anorganische u. Physikalische Chemie, Technische Universität Darmstadt,Petersenstr. 20, D-64287 Darmstadt (Germany)

* Corresponding author: e-mail dangsheng@ @hi-berlin.mpg.de,

Received 16 October 2008; accepted 28 February 2009, Available online 9 March 2009.

\begin{abstract}
For many years the scientific community has believed in a promising future for carbon nanotubes for various applications in such diverse fields as polymer reinforcement, adsorption, catalysis, electronics and medicine. Industrial production of carbon nanotubes and -fibers and the subsequent availability and decrease of price, have rendered this vision feasible. In the last years, several carbon nanomaterial products have been marketed by major chemical companies. In this work, we present an extensive characterization of a representative set of commercially available carbon nanomaterials. Special focus has been put on their quality, i.e. presence of metal or carbonaceous impurities but also homogeneity and structural integrity. The observations are of importance for subsequent use in catalysis where the presence of impurities or defects in the nanostructure can dramatically modify the activity of the catalytic material.
\end{abstract}

\section{Introduction}

Correlating the properties of carbon materials to their bulk or surface structures remains a major topic of research. Already in the early 1930s, Hofmann and Lemcke tried to find correlations between the structure of activated carbons and their catalytic activity [1]. Since then our knowledge has significantly improved [2-7]. Carbonization and graphitization mechanisms seem to be well understood. The structure and the chemistry of defects and vacancies have also been largely studied [8-12].

Research in this field has been again boosted by the first TEM images of carbon nanotubes (CNTs) published in the early 1950s [10, 13] and especially by Iijima's 1991 report [14]. Carbon nanotubes exhibit a variety of interesting properties: high mechanical strength, high thermal conductivity, high electrical conductivity and good chemical stability in aggressive media, among others $[15,16]$. Recently, it was also reported that their inner tubule can be used to host inorganic nanowires and nanoparticles, or even be employed as a nanoreactor for carrying out catalytic reactions $[17,18]$. Finally, their surface can be easily functionalized, i.e. chemically modified, to improve their dispersion in solvents and anchor transition metals for application as catalyst support, or to attach organic molecules, thus transforming them into a selective drug vector [19]. Much progress has already been made in their synthesis, their characterization, and processing for further application [16, 20-27], however the structural parameters critical for each application still need to be identified.

The mechanical and conductive properties of carbon nanomaterials were the first to have practical applications. With a Young's modulus of approximately $1 \mathrm{TPa}$ and a tensile strength of approximately $50 \mathrm{GPa}$, carbon nanotubes are the strongest and stiffest nanomaterials [21, 25, 27, 28]. Their advantages for polymer reinforcement have been recently reviewed by Miyagawa et al. and Coleman et al. $[29,30]$. Koziol et al. spun fibers from CNTs much stronger than in previous studies [31]. Such fibers can be imagined as a superior alternative to Kevlar. CNTs are also 
used commercially as conductive additive to polymers and plastics [32]. This application found interest in the automotive industry for static-dissipative fuel-handling components and for conductive body panels that allow electrostatic painting $[33,34]$. The fast deployment of these applications is a result of the extensive research that has already been done over the past decades in this field to use and integrate carbon microfibers [35]. Other fields like electronics [36], catalysis [37, 38] or medicine [39] are more challenging. More research and development are needed before commercialization of a product or process integrating carbon nanotubes. Many parameters need to be controlled both on a macro and nano level: homogeneity, purity and porosity of the material but also tortuousness/straightness, graphitic character, presence of defects and chemical state of the CNT surface. Moreover, the effect of each of these parameters is not yet fully understood. In electronics, the defects and the presence of functional groups (heteroatoms) or adsorbed molecules are of major importance because they influence the electronic conductivity and the ballistic transport of the electrons [36, 40]. In catalysis, porosity, defects and chemical state of the surface are the main parameters to control because they directly influence the active phase dispersion and can influence the catalytic activity of the transition metals [7, 41]. In medicine, the impurities and chemical state of the surface are critical parameters to ensure the biocompatibility and the anchoring of drugs $[19,42]$. For example, iron, which is the catalyst most often used to grow carbon nanotubes and which is often found as impurity in the final product, was shown to be cytotoxic for brain cells [43]. Recently, it was also shown that the cytotoxicity is greatly influenced by the functional groups present on the carbon surface [44-46].

Many studies were conducted with CNTs produced by catalytic chemical vapor deposition (CCVD) with bench-scale setups. Experimental parameters such as catalyst particle size, catalyst reduction conditions, nature of the carbon feedstock, temperature, flow, design of the reactor, etc, drastically influence the homogeneity and purity of the sample as well as the morphology, structure and quality of the CNTs [27, 47, 48]. Clearly, reproducibility and even repeatability remain problematic [49]. This situation is expected to improve as major chemical companies start to market commercial high purity ( $>95 \%$ ) carbon nanotubes at low prices, below $200 € / \mathrm{kg}$. Worldwide, about 35 suppliers of multiwall carbon nanotubes (MWCNTs) can be found, the most important being Bayer (Germany), Nanocyl (Belgium), Arkema (France), Hyperion (USA), Iljin Nanotech (South Korea) and Shenzhen Nanotech Port (China) [34]. As the carbon nanotube market is expected to jump from \$215 million in 2009 to $\$ 1$ billion in 2014 and finally $\$ 9.4$ billion in 2020 [34, 50], a great effort is expected from these companies to increase the production and at the same time assure a stable level of quality. Some of them are already producing MWCNTs on a metric ton scale. In 2006,
Arkema inaugurated a 10T/year pilot plant ${ }^{1}$. Nanocyl recently increased its production to $40 \mathrm{~T} / \mathrm{year}^{2}$. In September 2007, Bayer inaugurated a second 30T/year plant, thus increasing its production capacity to $60 \mathrm{~T} / \mathrm{year}^{3,4}$. Further plans of the company include a scale-up to 200 and finally $3000 \mathrm{~T} / \mathrm{year}$ by $2011^{5}$. The availability for the whole scientific community of reproducible, homogeneous carbon nanomaterials was a prerequisite. Now that these materials exist, they need to be systematically characterized and their structure needs to be understood [49]. It is worth noting that only few extended characterizations of carbon nanotubes, for which data was analyzed in depth, can be found in the literature [51].

The aim of the present work is twofold: (i) to establish protocols for the characterization of carbon nanostructures and the careful interpretation of the experimental data, and (ii) to provide a comprehensive characterization of selected commercially available samples using common techniques. The carbon nanostructures used in the present work are already produced on a metric Ton scale and have found applications in the literature and in industry. Pyrograf Products materials have existed for many years and are widely used in the polymer field to replace carbon microfibers in carbon-carbon composites [35]. Baytubes and NC 3100 are the leading MWCNTs products of the two biggest producers in Europe, Bayer MaterialScience and Nanocyl, respectively.

\section{Experimental}

\subsection{Pristine carbon nanomaterials}

Vapor-grown carbon nanofibers (VGCNFs) were purchased from Pyrograf Products Inc. (Ohio, USA). Multiwall carbon nanotubes were supplied by Bayer MaterialScience AG (Germany) and Nanocyl S.A. (Belgium). Exact product names, batch numbers and average outer diameter as provided by the producers are reported in the Supplementary Material. The MWCNT products were all given with a carbon purity higher than $95 \%$. The Pyrograf carbon nanofiber products differ in their average outer diameter (PR24 vs. PR19) and their grade (PS, LHT or HHT). The as-grown nanofibers underwent a post-treatment at various temperatures to remove the polyaromatic carbon layer covering their outer surface. The treatments were carried out at

\footnotetext{
${ }^{1}$ Arkema. Graphistrength Multi-wall Carbon Nanotubes. http://www.graphistrength.com. October 2, 2008.

${ }^{2}$ Nanocyl: the carbon nanotube specialist. http://www.nanocyl.com. November 22, 2007. ${ }^{3}$ Bayer MaterialScience. Carbon nanotube capacity expanded. http://www.press.bayerbms.com. September 5, 2007.

${ }^{4}$ Bayer MaterialScience. Baytubes webpage. http://www.baytubes.com. October 2, 2008.

${ }^{5}$ Bayer MaterialScience. Baytubes capacities. http://www.baytubes.de/product_production/baytubes_capacities.h tml. October 2, 2008
} 
700, 1500 and $3000^{\circ} \mathrm{C}$ for the PS, LHT and HHT grades, respectively.

\subsection{Functionalization of the carbon nanomate- rials}

PR24-LHT and Baytubes were treated with concentrated nitric acid (70\%, Sigma-Aldrich) under vigorous magnetic stirring at $100^{\circ} \mathrm{C}$ for $2 \mathrm{~h}$ and $10 \mathrm{~h}$. The treatment was performed at a temperature below the boiling point of nitric acid $\left(130^{\circ} \mathrm{C}\right)$ to avoid thermal degradation of $\mathrm{HNO}_{3}$ and loss as gaseous $\mathrm{NO}_{2}$. The ratio of nitric acid to carbon sample was set to $500 \mathrm{ml}$ for $10 \mathrm{~g}$. This ratio was expected to be sufficient to avoid changes in the nitric acid concentration due to consumption. After treatment, the solution was allowed to cool down to room temperature. It was then filtered and the carbon sample was thoroughly rinsed with 11 distilled water. The samples are labeled PR24LHT-2h and Baytubes-2h for the samples treated with $\mathrm{HNO}_{3}$ for 2 $\mathrm{h}$, and PR24LHT-10h and Baytubes-10h for those treated for $10 \mathrm{~h}$.

\subsection{Sample characterization}

The characterization procedures were optimized for carbon nanomaterials. However, the standard acquisition methods delivered with the commercial softwares were typically preferred in order to allow for an easy comparison with our data. We provide here a detailed experimental section as an attempt of a standard protocol for characterizing carbon nanomaterials.

The presence of metal impurities in the different samples like remaining catalyst and/or catalyst support was checked by wavelength dispersive X-ray fluorescence (WDXRF) using a Bruker S4 Pioneer spectrometer. Typically, $0.5 \mathrm{~g}$ of sample was deposited inside a polystyrene holder (34 mm in diameter) and covered with a $4 \mu \mathrm{m}$ polypropylene foil. Other sample preparation techniques like pressing or mixing with a matrix were avoided in order to prevent from any additional impurities. Standardless measurements were performed under helium, using the MultiRes-He34 acquisition program delivered with the SPECTRA $^{\text {plus }}$ software from Bruker. The detected impurities were then further quantified at the SGS Institut Fresenius GmbH (Taunusstein, Germany). Transition metal impurities were measured by inductively coupled plasma atomic emission spectrometry (ICP-AES) using the norm EN ISO 11885, after dry ashing of the samples, fluorination with $\mathrm{H}_{2} \mathrm{SO}_{4} / \mathrm{HF}$ and treatment with $\mathrm{HCl}$. Nitrogen was quantified by combustion of the sample in oxygen followed by thermal conductivity measurements $\left(\mathrm{NO}_{\mathrm{x}}\right)$. For the determination of sulfur content, the sample is also combusted in an oxygen stream at ca. $1400^{\circ} \mathrm{C}$. The produced $\mathrm{SO}_{2}$ is transferred into a measuring cell filled with diluted $\mathrm{H}_{2} \mathrm{SO}_{4} / \mathrm{H}_{2} \mathrm{O}_{2}$ solution. The change in conductivity is measured using a relative conductometry detector.
Specific surface areas were determined from $\mathrm{N}_{2}$ adsorption-desorption at liquid nitrogen temperature $(77 \mathrm{~K})$ using a Quantachrome Autosorb-6B KR sorptometer. Measurements were performed on 30 and $80 \mathrm{mg}$ for low and high surface area samples, respectively. Data were analyzed with the Autosorb Multistation software from Quantachrome. Prior to measurement, the samples were outgassed for $4 \mathrm{~h}$ under vacuum at $120^{\circ} \mathrm{C}$ and $225^{\circ} \mathrm{C}$ to remove moisture from the VGCNFs and MWCNTs samples, respectively. The total surface area was calculated using the BET equation. Pore size distributions were determined from the desorption branches of the isotherms using the BJH method. The micropore surface area was approximated using the t-plot method applied to the first 5 points of the adsorption branches of the isotherms.

X-ray diffraction powder patterns (XRD) were measured with a STOE STADI-P transmission diffractometer equipped with a focusing primary Ge (111) monochromator and a position sensitive detector (PSD), using $\mathrm{Cu} \mathrm{Ka}$ radiation. Small amounts of sample powder were sandwiched between two layers of X-ray amorphous polyacetate foil, fixed with small amounts of X-ray amorphous grease. The foil sandwich was clamped into a ring shaped transmission sample holder and rotated during measurement for better counting statistics. The PSD covers about $6^{\circ}$ 2theta with a physical resolution of $0.01^{\circ}$ 2theta per channel. The measurements were performed by moving the PSD in steps of $0.1^{\circ}$ theta with accumulation times of 10 seconds/step, successively summing up the counts collected by different channels for any given data point.

For morphological investigations of the carbon nanomaterials, a Hitachi S-5200 scanning electron microscope (SEM) was used. The samples were loosely dispersed on conductive carbon tape (Plano) to preserve the as-prepared morphology as much as possible. Images were acquired at different magnifications to show both the agglomeration of the tubes and the surface topography of the individual tubes. All images were acquired using an acceleration voltage of $2 \mathrm{kV}$ for better resolution of surface features.

The microstructure of the carbon samples was investigated by transmission electron microscopy (TEM). The investigation was conducted in a Philips CM200 TEM with a $\mathrm{LaB}_{6}$ emitter. The samples were dispersed in chloroform and deposited on a holey carbon film supported on a $\mathrm{Cu}$ grid. We preferred chloroform over other solvents like ethanol or acetone as we observed previously that these latter can remove or modify the layer of amorphous carbon covering Diesel soot particles. For high resolution imaging and electron energy loss spectroscopy (EELS) measurements, a similar microscope with a field emission gun was used. EEL spectra were recorded using a GATAN Tridiem image filter. The energy resolution, estimated from the fullwidth at half maximum of the zero-loss peak, was $1 \mathrm{eV}$. EEL spectra of at least 15 different areas were acquired and corrected for background and multiple scattering. They were then summed up in order to lead to an EEL spectrum representative of the sample. Statistical image analysis of 
both SEM and TEM images were done using Image-Pro Analyzer from Media Cybernetics. Digital Micrograph from Gatan was used for TEM images acquisition and for EEL spectra analysis.

For the Raman experiments the samples were introduced into an Au coated stainless steel sample holder with a $0.6 \mathrm{~mm}$ deep rectangular well covering an area of $(12 \times 8)$ $\mathrm{mm}^{2}$. Raman spectra were measured at room temperature using $514 \mathrm{~nm}$ laser excitation from a Ar ion laser (Melles Griot). The laser power was set to $3 \mathrm{~mW}$ as measured at the sample position. According to the manufacturer of the sampling optics used (Kaiser Optical) the spot size at the sample is $30-50 \mu \mathrm{m}$ in diameter. The backscattered light was analyzed using a Holoprobe Raman spectrometer (Kaiser Optical) equipped with a high performance holographic notch filter, a holographic grating and an electrically cooled CCD camera. The spectral resolution of the instrument is $5 \mathrm{~cm}^{-1}$, the reproducibility is better than $0.5 \mathrm{~cm}^{-1}$. Sampling times were typically $50 \mathrm{~min}$. Prior to the experiments, the Raman spectrometer was calibrated using an Ar lamp. For background subtraction the spectrum of the bare sample holder was used.

The X-ray photoelectron spectroscopy (XPS) measurements were carried out using a modified LHS/SPECS EA200 MCD system equipped with a $\mathrm{Mg} \mathrm{K}_{\alpha}$ source $(1253.6 \mathrm{eV}, 168 \mathrm{~W})$. The binding energy scale of the system was calibrated using $\mathrm{Au} 4 \mathrm{f}_{7 / 2}=84.0 \mathrm{eV}$ and $\mathrm{Cu} 2 \mathrm{p}_{3 / 2}=$ $932.67 \mathrm{eV}$ from foil samples. The powder samples were placed as-is in a stainless steel sample holder with a $0.6 \mathrm{~mm}$ deep rectangular well covering an area of $(12 \times 8) \mathrm{mm}^{2}$. During the XPS experiments the pressure was about $1 \times 10^{-9} \mathrm{mbar}$. Impurities were detected in the constant retard ratio mode. For quantitative data analysis, the spectra were recorded with the constant pass energy mode and the data analysis was performed on the basis of peak areas by fitting with 30/70 Gauss-Lorentz product functions after subtraction of a Shirley background. Atomic ratios were calculated using atomic sensitivity factors [52]. Additional XPS experiments were performed at the ISISS beamline at the BESSY synchrotron facility in the end station of the FHI-MPG. Samples were transferred into the reaction cell, $\sim 2 \mathrm{~mm}$ away from an aperture to the differentially pumped stages of the lens system of the hemispherical analyser Phoibos 150 (SPECS). The probe size was $\sim 100 \mu \mathrm{m}$ to 1 $\mathrm{mm}$. All spectra are collected in normal emission geometry at photon energies of 405 and $585 \mathrm{eV}$ for the $\mathrm{C} 1 \mathrm{~s}$ region and 650 and $830 \mathrm{eV}$ (only the higher energies were used for the $\mathrm{O} 1 \mathrm{~s}$ region), respectively, with a spectral resolution of $\sim 0.3 \mathrm{eV}$. For these photon energies, the electron mean free path varies between 6 and $8 \AA$ [53].

Temperature programmed oxidation (TPO) of the samples was carried out with a Netzsch STA 449 thermobalance for simultaneous TG-DSC. The apparatus was equipped with a Pfeiffer OmniStar ${ }^{\mathrm{TM}}$ mass spectrometer for gas phase analysis. Typically $5 \mathrm{mg}$ of sample were put in an $85 \mu \mathrm{l}\left(6.8 \mathrm{~mm}\right.$ in diameter) $\mathrm{Al}_{2} \mathrm{O}_{3}$ crucible. The TPO experiments were carried out using a $100 \mathrm{ml} \cdot \mathrm{min}^{-1}$ flow of

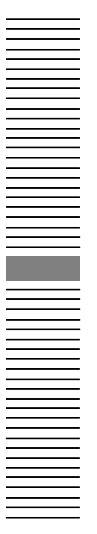

a

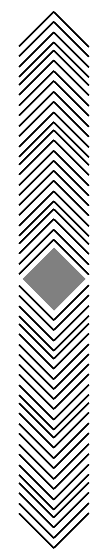

b

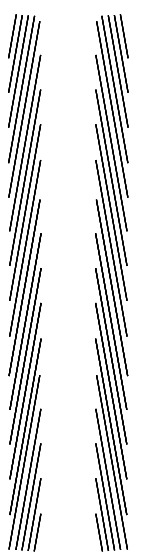

C

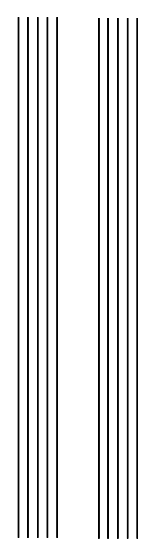

d
Fig. 1: Schematic representations of a) platelet $\mathrm{CNF}$, b) fishbone CNF, c) hollow CNF and d) MWCNT. In the morphology-based definition, both $\mathrm{c}$ and $\mathrm{d}$ can be called multiwall carbon nanotube although they do not present the same structure. Only $d$ is a MWCNT in Dresselhaus and Endo's definition.

$20 \% \mathrm{O}_{2}$ in Ar. The temperature was ramped from 30 to $1150^{\circ} \mathrm{C}$ at $2^{\circ} \mathrm{C} \cdot \mathrm{min}^{-1}$ and then held for $30 \mathrm{~min}$

Zeta potential measurements of the nitric acid treated samples were performed using a Malvern Instruments Ltd. ZEN 3600 Zetasizer, equipped with a $633 \mathrm{~nm}$ laser, in combination with a MPT-2 auto-titrator. A small amount of carbon sample was first dispersed in distilled water with the help of an ultrasonic bath. The solution was then filtered with a $5 \mu \mathrm{m}$ filter in order to remove aggregates. The measurements were performed with a DTS $1060 \mathrm{C}$ cell at a constant temperature of $25^{\circ} \mathrm{C}$. The $\mathrm{pH}$ of the solution was decreased from $\mathrm{pH}=11$ to $\mathrm{pH}=1.5$ with a step of 0.2 using a $0.25 \mathrm{M} \mathrm{HCl}$ solution. A delay of $20 \mathrm{~s}$ was allowed between each measurement. Data were acquired and analyzed with the Marvin software from the same company.

\section{Results and discussion}

\subsection{CNT and CNF definitions}

Surprisingly, there is no general agreement in the literature on the definition of "multiwall carbon nanotubes". This discrepancy probably finds its origin in the contradictory studies carried out to determine the structure of MWCNTs. Whereas Ijima supported a structure made of coaxial singlewall carbon nanotubes arranged in a "Russian doll" fashion [14], later reports indicated that MWCNTs could actually be made of a scrolled single graphene sheet [54], similar to the graphite whiskers extensively studied by Bacon [55]. The existence of ribbon-like nanofibers with graphene layers stacked parallel to the growth axis added even more confusion [56]. Two definitions have dominated the literature. One is based on morphology, the other on structure. In the morphological definition, which is the most common, a carbon nanotube is defined as any graphit 
Table 1. Inorganic impurities detected by WDXRF in the different commercial samples and their concentration (in \%) determined by elemental analysis (in brackets).

\begin{tabular}{ccc}
\hline Sample name & Main impurities & Trace impurities \\
\hline PR24-PS & $\mathrm{Fe}(1.47), \mathrm{S}(0.34)$ & $\mathrm{Mg}, \mathrm{Cl}, \mathrm{Ca}, \mathrm{Cr}$ \\
PR24-LHT & $\mathrm{Fe}(1.27), \mathrm{S}(0.31)$ & $\mathrm{Ca}$ \\
PR24-HHT & $/$ & $/$ \\
PR19XT-PS & $\mathrm{Fe}(1.27), \mathrm{S}(0.12)$ & $/$ \\
PR19XT-LHT & $\mathrm{Fe}(1.19), \mathrm{S}(0.17)$ & $/$ \\
PR19XT-HHT & $/$ & $\mathrm{Jl}(0.49), \mathrm{Mg}(0.56)$ \\
Baytubes $^{\circledR}$ & $\mathrm{Co}(0.78), \mathrm{Mn}(0.75)$ & $\mathrm{Al}(0.03)$ \\
NC 3100 & $\mathrm{Fe}(0.19), \mathrm{Co}(0.07), \mathrm{S}(0.14)$ & \\
\hline
\end{tabular}

Table 2. Specific surface areas determined by $\mathrm{N}_{2}$ adsorption. The micropore areas were approximated using the t-plot method.

\begin{tabular}{|c|c|c|}
\hline Sample name & BET area $\left(\mathrm{m}^{2} \cdot \mathrm{g}^{-1}\right)$ & Micropore area $\left(\mathrm{m}^{2} \cdot \mathrm{g}^{-1}\right)$ \\
\hline PR24-PS & 43 & 0 \\
\hline PR24-LHT & 32 & 13 \\
\hline PR24-HHT & 34 & 9 \\
\hline PR19XT-PS & 31 & 0 \\
\hline PR19XT-LHT & 16 & 3 \\
\hline PR19XT-HHT & 25 & 0 \\
\hline Baytubes $^{\circledR}$ & 288 & 40 \\
\hline NC 3100 & 334 & 59 \\
\hline PR24LHT-2h & 37 & 5 \\
\hline PR24LHT-10h & 43 & 10 \\
\hline Baytubes-2h & 321 & 38 \\
\hline Baytubes-10h & 337 & 36 \\
\hline
\end{tabular}

ic carbon material of nanometric size having a tubular shape, i.e. a cylinder with a tubular cavity. Following this definition, the main discrepancy between a nanotube and a nanofiber is the lack of a hollow cavity for the latter [38]. The second definition, used by Dresselhaus and Endo, defines it as a nested coaxial array of single-wall nanotube, each nanotube being formed by a graphene sheet rolled into a cylinder of nanometer size diameter (Fig. 1d) [57]. The morphology-based definition clearly induces a semantic problem as it does not distinguish between materials exposing basal planes and materials exposing prismatic planes (Fig. 1c and 1d). As these surface characteristics strongly affect the physico-chemical properties of the material, they are of paramount importance in e.g. catalysis and a standard definition should be unambiguous on this. For example, carbon materials from Pyrograf Products that are known to be vapor-grown carbon nanofibers (VGCNFs) $[35,58-61]$ are also sometimes referred to as multiwall carbon nanotubes in the literature due to their quasi-parallel outer walls and large internal channel [62-65]. In order to avoid any ambiguity in the present work, and in the literature in general, we suggest to generalize the definition used by Dresselhaus and Endo [57].

\subsection{Synthesis of the studied carbon nanostruc- tures}

Details about Pyrograf products, Baytubes and NC 3100 synthesis can be found in previous reports and patents [35, 58-61, 66-70]. Briefly, Pyrograf VGCNFs are synthesized by feeding a mixture of $\mathrm{CH}_{4}, \mathrm{NH}_{3}$, Air, $\mathrm{H}_{2} \mathrm{~S}, \mathrm{Fe}(\mathrm{CO})_{5}$ in a horizontal reactor maintained at $1100^{\circ} \mathrm{C}$. The iron carbonyl is decomposed and activated with the hydrogen sulfide. In the reactor, nanoparticles are formed and remain suspended in the gas phase and subsequently catalyze the growth of carbon nanofibers. The design of the reactor makes the VGCNFs clog the outlet of the reactor for a short time before they are able to exit the heated zone. Then follows a thickening step during which the methane is thermally cracked on the carbon surface, yielding an amorphous or highly disordered carbon deposit that homogeneously covers the surface of the catalytically grown hollow carbon nanofiber. This carbon deposit can either be partially removed or graphitized by post-treatment at high temperature in inert atmosphere. The as-grown VGCNFs (AS grade) can be treated at $700^{\circ} \mathrm{C}$ (pyrolitically striped, PS grade), $1500^{\circ} \mathrm{C}$ (LHT grade) or $3000^{\circ} \mathrm{C}$ (HHT grade). 
Two different products are currently on the market, PR-19 and PR-24. They are given with an average outer diameter of $150 \mathrm{~nm}$ and $100 \mathrm{~nm}$, respectively ${ }^{6}$.

Multiwall carbon nanotubes from Bayer MaterialScience and Nanocyl are grown by catalytic chemical vapor deposition (CCVD) in a fluidized bed reactor [67, 69, 70]. The carbon source (hydrocarbon) is decomposed on a solid catalyst and MWCNTs are grown around the catalyst grain. In the case of the Nanocyl product, part of the catalyst is then removed during a purification step carried out by the company. For the Baytubes, the yield is sufficiently high to guarantee a purity higher than $95 \%$ without further purification. Both products are supposed to consist of carbon nanotubes with diameters of approximately $10 \mathrm{~nm}$, free of any amorphous carbon. However, no information is provided concerning the nature of the impurities and the microstructure of the carbon nanotubes.

\subsection{Characterizations of the carbon nanomate- rials}

\subsubsection{Elemental analysis}

The different samples were first analyzed by WDXRF. This technique shows a high sensitivity to most of the elements of the periodic table between $\mathrm{Na}$ and $\mathrm{U}$, down to sub-ppm levels. Results are reported in Table 1. As expected, all the samples contain growth catalyst impurities, mainly Fe and Co. Sulfur was found in the Pyrograf Products samples, as expected from the synthesis conditions. More surprisingly, sulfur was also found in the Nanocyl nanotubes. Patents from Nanocyl do not mention the addition of sulfur containing compounds to improve the activation of the catalyst or the growth of the nanotubes. Thus, the presence of sulfur is, in this case, probably due to the purification process. It seems that Nanocyl post-treats its product with sulfuric acid to remove the catalyst. From the PR24-LHT and PR19XT-LHT samples, it appears that the sulfur is strongly bonded to the VGCNF sample, either to the catalyst or to the carbon backbone. Treatment in inert gas at $1500^{\circ} \mathrm{C}$ did not significantly decrease the sulfur content. The impurities detected by WDXRF were further quantified using ICP-AES (Table 2). Concentrations of the individual impurities were typically lower than $2 \%$. Thermogravimetric analyses (TGA) also confirmed that in all cases, the purity was higher than the products specifications, i.e. $95 \%$ (see below).

\subsubsection{Scanning electron microscopy}

Low magnification SEM images (Fig. 2) show major differences between the various nanocarbon samples investigated. Baytubes and NC 3100 tubes formed large agglo-

\footnotetext{
${ }^{6}$ Pyrograf Products Inc webpage.

http://www.pyrografproducts.com. October 2, 2008.
}

merates, ranging from ca. $100 \mu \mathrm{m}$ to several hundreds of micrometers (Fig. 2a and c). The agglomerate sizes for the Pyrograf Products samples were all smaller than this, ranging generally from $10-100 \mu \mathrm{m}$ for the PR24 samples and from 100-200 $\mu \mathrm{m}$ for the PR19XT samples (Fig. 2e and 2f). Generally the PR24 samples seemed more densely packed than the PR19XT samples. This originates from the postsynthesis debulking method used by Pyrograf Products. The debulking consists of decreasing the diameter of the fiber clumps using a milling process [35]. "XT" products present a lower density, thus making the dispersion of the carbon nanomaterial in polymers easier. For the NC 3100, the nanotubes formed rope-like structures with rope diameters up to ca. $5 \mu \mathrm{m}$ in diameter (Fig. 2a). Such structures were not observed for any of the other samples. The individual ropes were highly entangled (Fig. 2b). For the Baytubes sample, a high degree of entanglement was found throughout the agglomerates, straight tubes were rarely observed (Fig. 2c-d). For both NC 3100 and Baytubes, the nanotubes grow all around the primary catalyst grains, keeping the general shape of the starting catalyst grain. This entanglement leads to MWCNTs grains with a high mechanical resistance. For example, treating the Baytubes sample with nitric acid using a stirring rate of $500 \mathrm{rpm}$ led to a clear solution, even after $10 \mathrm{~h}$, thus indicating that attrition was rather limited. SEM images also confirm that the grain shape and size were not significantly affected during the functionalization step.

Whereas the nanotubes from Bayer MaterialScience and Nanocyl all showed smooth surfaces, the Pyrograf Products VGCNF had more structure on the external surfaces. For all the Pyrograf Products samples, bamboo-like nanofibers were also observed. For the sample treated at the lowest temperature $\left(\mathrm{PS}, 700^{\circ} \mathrm{C}\right.$ ) the surface of the fibers appeared smooth with only little structure. For the sample treated at higher temperature (LHT, $1500^{\circ} \mathrm{C}$ ) some fibers exhibit a non-circular cross section, but rather a polygonal cross section. A few of the largest LHT fibers appeared to have a more wrinkled surface (Fig. $2 \mathrm{~g}$ ). Such surfaces were only observed for this sample. The high-temperature treated sample (HHT, $3000^{\circ} \mathrm{C}$ ) showed mainly fibers with polygonal cross sections (Fig. 2h). Dresselhaus et al. reported similar observation for VGCNFs [2]. They proposed that the fiber becomes more faceted and exhibits a more flat graphite-like structure because of the strong interplanar correlations resulting from the facets. On many fibers the terminating graphene sheets of the fishbone type structure could also be observed. It appears that after graphitization above $2800^{\circ} \mathrm{C}$ the graphene sheets parallel to the fiber axis get reorganized and the overall structure recrystallizes to form a fiber made of a stacking of conical highly graphitic crystallites [35]. Another characteristic of all Pyrograf Products fibers is the shape of the fiber tips. Most often the inner catalytically grown graphitic layer is observed to protrude from the coating layer (Fig. 2g), i.e. sword-insheath failure $[2,71]$. In many cases the termination has a conical shape at one end of the tube. 

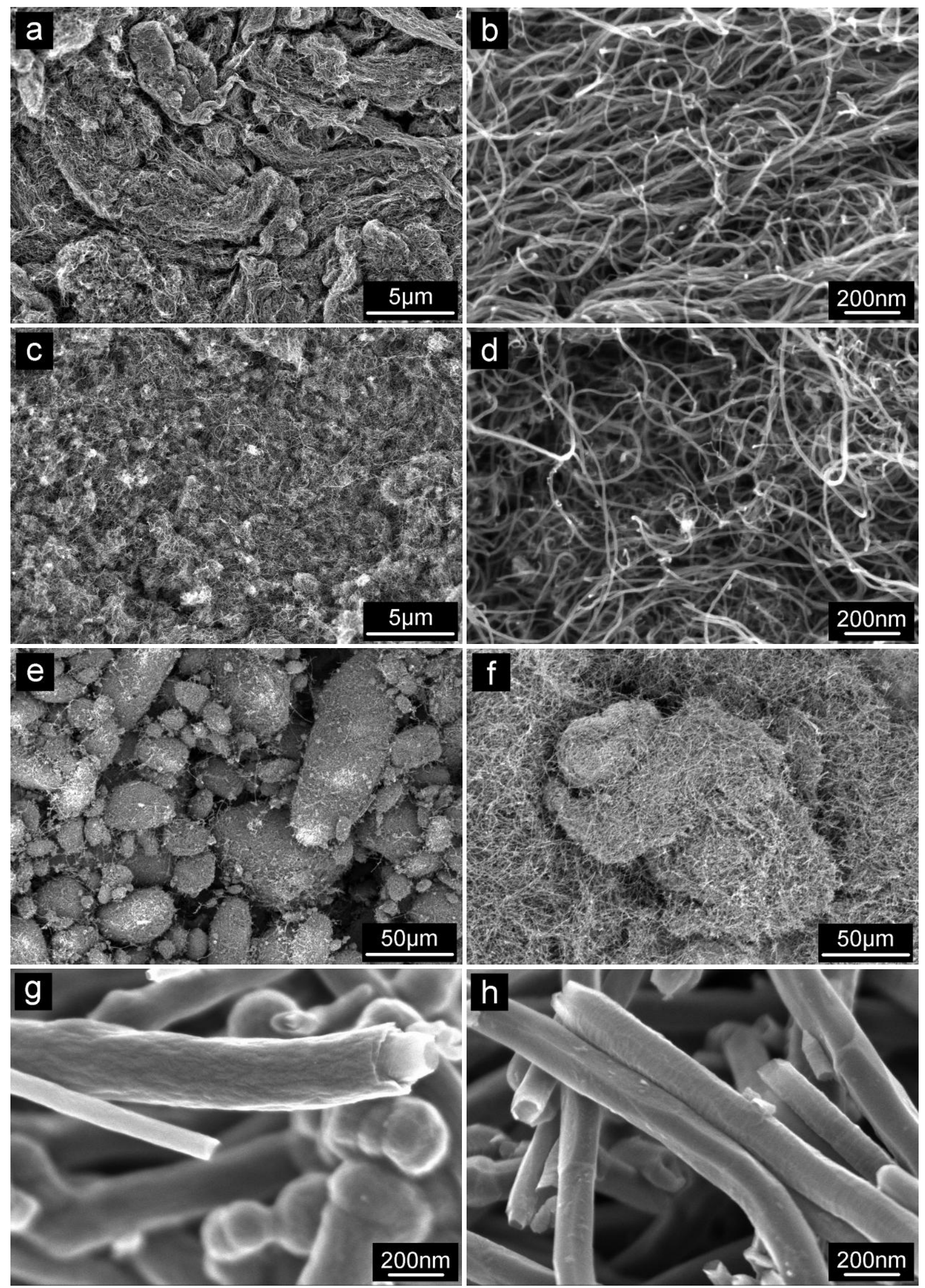

Fig. 2: SEM images of the NC 3100 (a, b), Baytubes (c,d), PR24-PS (e), PR19XT-PS (f), PR19XT-LHT (g) and PR19XT-HHT (h)

For the Pyrograf Products PS and LHT samples, small metal particles were observed on the surfaces of the tubes in the backscattered electron images. These particles are most likely left behind from the growth process. Particle diameters are in some cases up to $20 \mathrm{~nm}$. For the Bay 

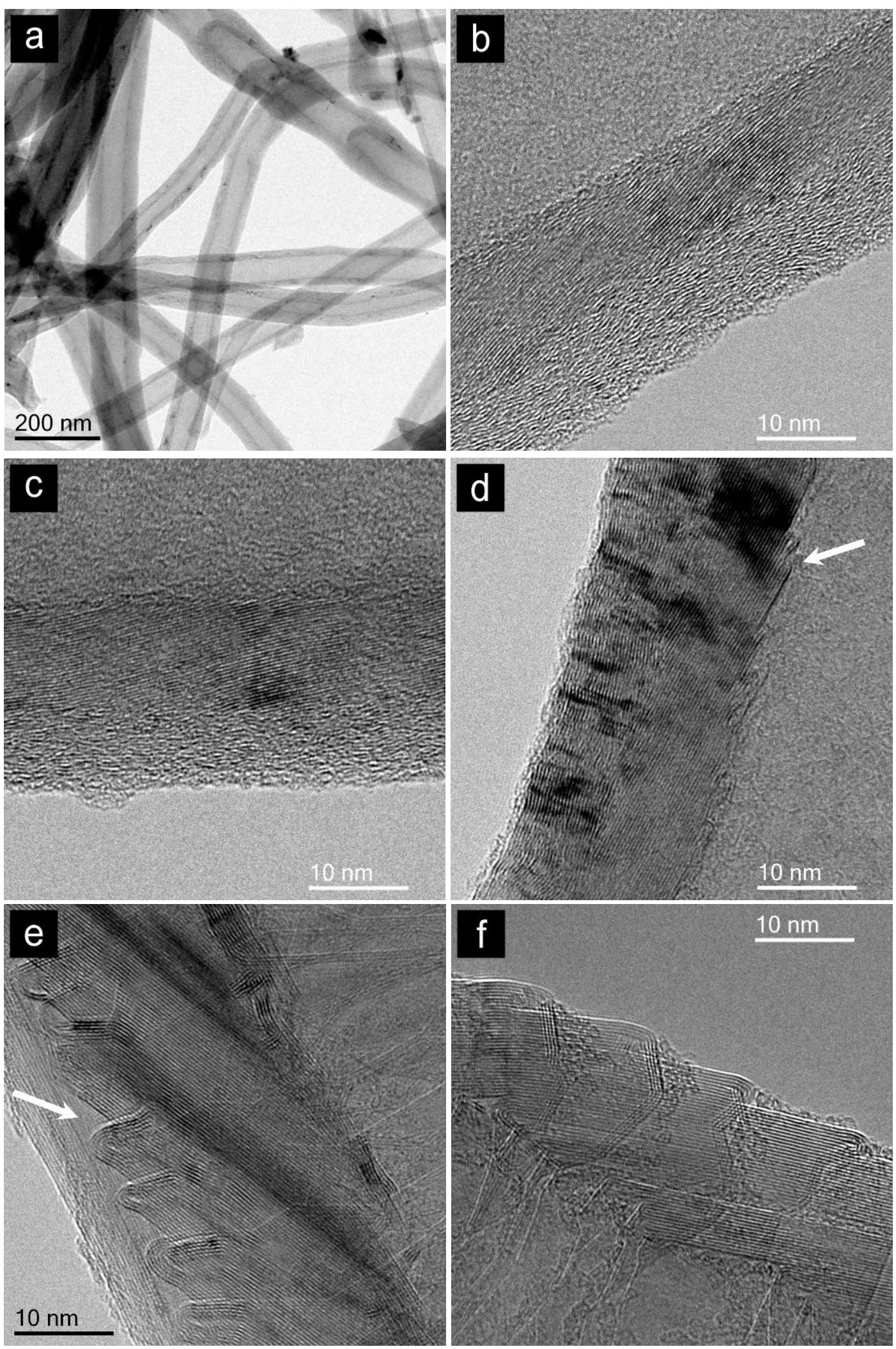

Fig. 3: Representative overview TEM image of the PR24 samples (a), and high resolution images of PR24-PS (b), PR19XT-PS (c), PR19XTLHT (d), PR19XT-HHT (e) and PR24-HHT (f). At $1500^{\circ} \mathrm{C}$, neighboring graphene sheets often connect (arrow in d). At $3000^{\circ} \mathrm{C}$, voids are observed between the core and the outer wall layer (arrow in e)

tubes, such particles were also observed, but only at the apex of the tubes.

One of the most noticeable differences between the samples is the difference in tube (MWCNT or hollow
VGCNF) diameters. For each sample, the outer diameters of more than 250 tubes were measured (see Supplementary Material). All the samples from Pyrograf Products have rather large outer diameters, with averages of $85 \mathrm{~nm}$ and 

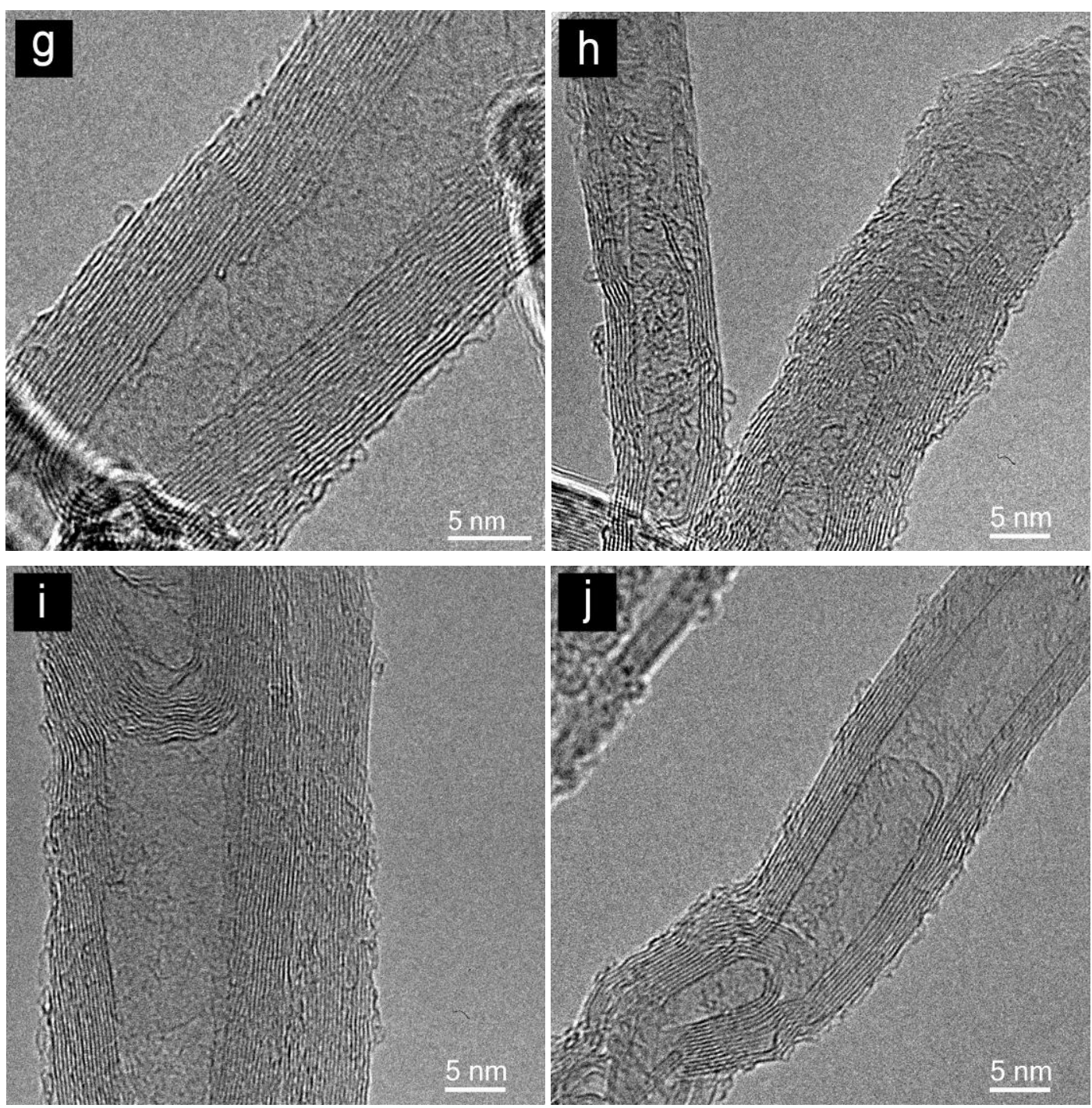

Fig.3 (continued): HRTEM images of the Baytubes (g-i) and NC 3100 samples (j).

$110 \mathrm{~nm}$ for the PR24 and PR19XT products respectively, much smaller than the average diameters indicated by the manufacturer. The distributions were all quite wide with tubes ranging from a few tens of nanometers to a few hundreds of nanometers. For the Pyrograf Products PR24 samples, tubular structures with diameters as large as $5 \mu \mathrm{m}$ were encountered. For the multiwall carbon nanotubes from Bayer MaterialScience and Nanocyl, much smaller diameters were observed, both with average outer tube diameter around $10 \mathrm{~nm}$ and narrow size distributions with standard deviations around $2.5 \mathrm{~nm}$.

\subsubsection{Transmission electron microscopy}

Transmission electron microscopy is a particularly valuable technique for characterizing carbon nanostructures as it provides information on the homogeneity of the sample, on the morphology of the nanostructures, on their microstructure (orientation of the walls and graphitic character) and on the presence of carbon or metal impuri- ties. Representative TEM and HRTEM images of the various samples are shown in Fig. 3. Internal and external diameters of approx. 200 tubes were measured from TEM images. The mean diameters are along with the standard deviations of the diameter distributions and the number of tubes measured (see Supplementary Material).

The hollow vapor grown carbon nanofibers from Pyrograf Products show a dual-wall structure (Fig. 3a-d). The core layer is a catalytically-grown hollow fishbone-type carbon fiber whereas the outer layer consists of disordered, pyrolytically grown walls, parallel to the main axis of the fiber [35]. Significant differences in the microstructure of the fibers are also observed for the three grades, i.e. PS, LHT and HHT (Fig. 3b-f). The inner core is well graphitized, even for the samples post-treated at the lowest temperature (PS grade, Fig. 3b-c). Each graphene sheet can easily be followed from the central tubule to the interface between the two wall layers. The angle between the graphene sheets and the main axis of the fiber is smaller than what is typically observed for fishbone structures, i.e. 10- 
$15^{\circ}$ instead of $45^{\circ}$. Consequently, the inner walls seem to be almost parallel to the main axis, like for MWCNTs. However, high resolution images clearly show the terminating prismatic edges. The samples treated at $1500^{\circ} \mathrm{C}(\mathrm{LHT}$ grade, Fig. 3d) mainly present the same structure. Occasionally, two terminating graphene sheets are linked to each other forming a small conical connection (arrow on Fig. 3d). This phenomenon is more prominent for the sample post-treated at $3000^{\circ} \mathrm{C}$ (HHT grade). Almost no prismatic edges could be observed anymore (Fig. 3e-f). Ugarte made similar observations when analyzing the structure of graphitic soot particles generated during the arc-discharge synthesis of $\mathrm{C}_{60}$ [72]. He saw that at the high temperatures present in the arc discharge experiments, (100) basal planes bend by $360^{\circ}$ and connect with another plane of the surface to form a folded graphite sheet. This kind of structure minimizes the dangling bonds of the (100) planes and consequently also the energy of the system.

The outer wall layer undergoes even more drastic changes when post-treating the VGCNFs at various temperatures. For the PS samples, this outer wall layer is highly disordered and wraps the core fishbone-like fiber. The interface between the two walls is smooth and parallel without any voids. Because of the high temperature of the synthesis process, $1100^{\circ} \mathrm{C}$, the outer layer is not totally amorphous but already exhibits short and heavily buckled graphene sheets. The order of this layer improves for the LHT samples treated at $1500^{\circ} \mathrm{C}$. Each graphene sheet is still buckled but it is longer than for the PS sample. Oberlin made similar observations when studying the graphitization process of carbon [73]. She reported that in the range 1000$2000^{\circ} \mathrm{C}$, small graphitic domains appear that later connect to form large wrinkled graphene layers when raising the temperature. These layers untwist and straighten out at temperatures above $2000^{\circ} \mathrm{C}$, when carbon atoms start to become mobile. This straightening of the graphene sheets has also been clearly observed for the HHT samples, which have been post-treated at $3000^{\circ} \mathrm{C}$. Because of the high temperature of the treatment, the VGCNFs undergo a major structural rearrangement. For most of the fibers, the outer layer straightens out and aligned walls parallel to the main axis are formed (Fig. 3e). The interface between the outer wall layer and the inner fishbone-like core is no longer smooth and large voids of 2-3 nm are then formed (arrow on Fig. 3e). For some of the fibers, the outer layer completely disappears (Fig. 3f). Statistics on the outer diameter distribution obtained from both SEM and TEM images do not show any decrease of the outer diameter (see Supplementary Material). PS, LHT and HHT samples all have similar average diameter for both VGCNFs products, PR24 and PR19. It therefore appears that at $3000^{\circ} \mathrm{C}$, the carbon atoms are mobile enough to reorganize completely around the core of the fiber. The graphene layers then form large conical structures that stack along the main axis of the fiber. The edges of these cones are separated enough to appear in the SEM images as small lines perpendicular to the main axis of the fiber (Fig. 2h). These cones eventually sinter further and recrystallize into large prismatic domains that can also be seen by SEM for some of the fibers (Fig. $2 \mathrm{~h})$.

TEM images also reveal that all Pyrograf Products samples contain much debris of various size and shape. In general, fragments of tubular structures as well as carbon balls of few hundreds of nanometers can easily be found both by SEM and TEM. Smaller debris like highly disordered carbon and self-standing curled graphene sheets are found on the outermost surface and inside of the central channel of the VGCNFs.

The Baytubes and the NC 3100 nanotubes, which are both sold as MWCNTs, show a very different morphology than the Pyrograf Products samples. From TEM images, it seems that both products exhibit the same narrow tubular morphology. Statistics on the inner and outer diameter distribution show that they both have average inner and outer diameters of 4 and $10 \mathrm{~nm}$, respectively (see Supplementary Material). These values are in good agreement with the mean diameters obtained from SEM images.

Whereas the TEM images are very similar for both MWCNTs samples, HRTEM images show major differences. For the Baytubes sample, the walls are often parallel to the main axis of the tubes and seem to be well organized: single graphene sheets propagate over hundreds of nanometers. However, hollow fishbone-like structures with prismatic edges on both the external and internal surfaces of the tubes were also often observed (Fig. 3g). Most of the time, the internal prismatic plane is smooth, i.e. the graphene sheet terminations are well-aligned. The inner channel of the Baytubes is empty and accessible. However, in many cases, the sheets are longer and eventually form closures within the central channel (Fig. 3h). Such internal enclosures drastically lower the accessible internal surface area of the tubes.

For some images, asymmetric nanotubes could also be observed. Asymmetry often happens in the case of MWCNTs grown by CCVD. Whereas one side of the nanotubes shows straight walls, the other side presents a defective region where the walls are bent. In the case of the Baytubes, a more unusual observation was made: different numbers of walls were counted on each side of the same nanotube (Fig. 3i). This observation raises many questions concerning the growth process and the nanotube structure. The most reasonable explanation would be that additional incomplete walls were grown by pyrolytic decomposition of the hydrocarbon on one side of the nanotubes, in a similar way as for the VGCNFs. This hypothesis would require a more detailed investigation. However, the amount and the nature of the disordered carbon deposited on the surface of the nanotubes seem to support this idea. Most of the nanotubes exhibit graphene-like, disordered, carbon deposits all over their inner and outer surfaces. No apparent differences could be observed after treatment with nitric acid, thus indicating that the deposit is graphitic enough to be stable towards oxidation and removal by concentrated nitric acid at $100^{\circ} \mathrm{C}$. 
For the NC 3100 sample, the individual tube walls propagate over longer distances than for the Baytubes and terminations are only rarely encountered (Fig. 3i). Also, the nanotubes seem to be more homogeneous in structure. They almost always show aligned walls, parallel to the main axis of the nanotubes. They are undoubtedly very close to the ideal MWCNTs structure by Dresselhaus and Endo's definition [57]. Occasionally, tube closures inside the tubes were found. Knuckle-type structures are frequently observed where the individual tubes form angles. Such knuckles contain several graphene sheets forming a tube closure. No hollow fishbone-like tubes were found and little debris was observed in the interior of the tubes. The exterior surface of the tubes shows only few graphene sheet terminations and small amounts of debris. The structure of the debris is similar to that found on the Baytubes surfaces.

\subsubsection{Specific surface area measurements and poro- simetry.}

The specific surface area (SSA) is a critical parameter for applications in catalysis. The catalyst support must preferably possess a high surface area in order to allow a good dispersion of the active phase. The total surface area determined from the BET equation and the micropore surface area approximated using the t-plot method are reported in Table 2. The total surface area of the samples ranges from ca. $20 \mathrm{~m}^{2} \cdot \mathrm{g}^{-1}$ to more than $300 \mathrm{~m}^{2} \cdot \mathrm{g}^{-1}$. The surface area is much smaller in the case of the Pyrograf Products samples (PR24 and PR19XT) compared to Baytubes and NC 3100. This observation is in agreement with previous work of Peigney et al. who showed the correlation between specific surface area, carbon nanotube diameter and number of walls [74]. The isotherms of the Pyrograf Products samples show almost no hysteresis, thus indicating that they are mainly macroporous, with pores larger than $50 \mathrm{~nm}$ (Fig. 4a). Baytubes and NC 3100 MWCNTs present a typical type IV isotherm, with a clear hysteresis at high $\mathrm{P} / \mathrm{P}_{0}$. Surprisingly, the two samples show very different specific surface areas, although the diameter of the nanotubes is similar (see diameter distributions in the Supplementary Material). The pore size distribution calculated from the desorption branch of the isotherm using the $\mathrm{BJH}$ method shows a bimodal distribution (Fig. 4b): small pores, between 2 and $5 \mathrm{~nm}$ in diameter, which correspond to the inner channel of the nanotubes, but also larger pores, of 6 to $150 \mathrm{~nm}$, which are formed between the entangled nanotubes [74]. The contribution for pores between 6 and 150 $\mathrm{nm}$ is lower for Baytubes than for NC 3100, which tend to indicate that the Baytubes are less entangled. SEM images show that the Nanocyl MWCNTs form ropes (Fig. 2a), which might also create some additional porosity between adjacent nanotubes, as reported by Peigney et al [74]. For Baytubes, the treatment with nitric acid for $2 \mathrm{~h}$ or $10 \mathrm{~h}$ leads to a shift to smaller pore diameters, 5 to $60 \mathrm{~nm}$, which tend to indicate that the nanotubes are more entangled than in the starting sample.
The contribution from small pores, between 2 and 5 $\mathrm{nm}$, is also less pronounced for Baytubes than for NC 3100 . Baytubes show inner walls (Fig. 3h) that can partially close the inner channel and thus decrease the overall surface area. It is however worth noting that in many cases these additional inner walls do not completely block the inner channel, as the desorbed volume of nitrogen, for this contribution, is only $30 \%$ lower than for the Nanocyl sample. $\mathrm{N}_{2}$ can still diffuse and adsorb in the inner cavity. However, for applications in catalysis, one would expect important diffusion and mass transfer problems. Nitric acid is commonly used to open capped carbon nanotubes. In the present work, nitric acid treatments also appear to be efficient to further open the Baytubes. The SSA consequently increases from 288 to $337 \mathrm{~m}^{2} \cdot \mathrm{g}^{-1}$ after a $10 \mathrm{~h}$ treatment at $100^{\circ} \mathrm{C}$.
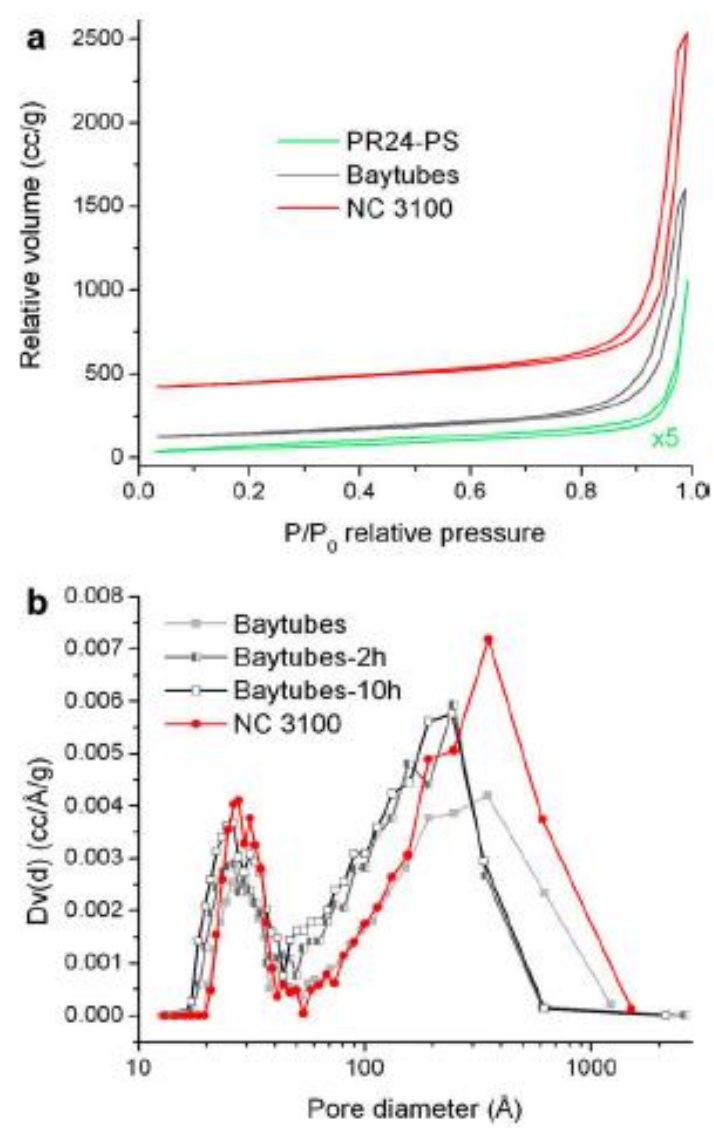

Fig. 4: (a)BET isotherms of the PR24-PS, Baytubes and NC 3100 samples. The isotherm of the PR24-PS sample has been magnified by a factor of 5 for easier comparison. (b) Pore size distributions of the Baytubes, Baytubes-2h, Baytubes-10h and NC 3100 samples

Many samples also develop a microporous surface area. This is rather unexpected as the tubular structure of these nanomaterials should only lead to mesoporosity. Microporosity is typically only observed in the case of singlewall carbon nanotubes. In the case of the multiwall carbon nanotubes (Baytubes, NC 3100), the micropores are decreased during the treatment with nitric acid. Thus, they must originate from the carbon deposits observed by 
HRTEM or from remaining catalyst. For the Pyrograf Products PR24 and PR19XT, the high temperature treatment leads to the graphitization of the dual wall structure, thus leading to an ill-defined structure and simultaneous creation of micropores, probably at the boundaries of the stacked conical crystallites.

\subsubsection{Powder X-Ray diffraction}

In addition to the morphology of the carbon nanomaterial, the graphitic character, i.e. the structural order, plays an important role. XRD should in principle bring valuable information. However, the interpretation of the diffraction pattern is not straight forward in the case of carbon nanotubes. Their size, their strong curvature which induces strain, as well as the disordered stacking of the graphene layers can lead to peak shifts, peak broadening and even to the suppression of some reflections. The position of the diffraction peaks may be explained by using the XRD pattern of graphite. However, deeper interpretation could be misleading because the CNTs do not present a 3D crystalline structure. Indeed, many groups already investigated disordered carbons by XRD [75-77]. They found that turbostratic carbon, which exhibits the same stacked graphene layers with a regular spacing as in graphite but different degree of stacking order, already shows a significantly different XRD pattern compared to hexagonal graphite. Therefore, it seems that in the case of CNTs, measuring the intensity of given peaks and the FWHM as well as using the Scherrer equation would have no physical meaning.

In the present case, it is however still meaningful to compare XRD patterns of nanomaterials having similar diameters (Fig. 5a-c). Pristine nanomaterials typically present weak and rather broad bands. The (002) peak seems slightly more intense in the case of the PR24-PS and PR19XT-PS samples compared to Baytubes and NC 3100 nanotubes, probably because their walls are thicker and therefore more prone to diffract. The high temperature post-treatments performed on the Pyrograf Products LHT and HHT samples dramatically modify the XRD patterns of these samples. The (002) peak becomes sharper, indicating that the order has been increased by this treatment. This observation is in line with previous work reporting that treatments in inert gas at $1500^{\circ} \mathrm{C}$ and above significantly improve the graphitic character of carbon materials [73]. The highly disordered carbon layer existing on the PS samples becomes ordered when treated at $1500^{\circ} \mathrm{C}$ or $3000^{\circ} \mathrm{C}$. The broad peak at around $43^{\circ}$ also becomes more intense and new diffraction peaks appear at $54^{\circ}$ and $78^{\circ}$ for the PR24-HHT and PR19XT-HHT samples. The diffraction peak at $54^{\circ}$ corresponds to the graphite- $2 \mathrm{H}(004)$ and can therefore directly be linked to the strong increase of the (002) peak. The broad band at $43^{\circ}$ is difficult to assign as both hexagonal and rhombohedral graphite lead to peaks between $42^{\circ}$ and $46^{\circ}$. The presence of rhombohedral graphite after the treatment at $3000^{\circ} \mathrm{C}$ is further confirmed by the graphite-3R (110) peak which appears at $78^{\circ}$. This peak
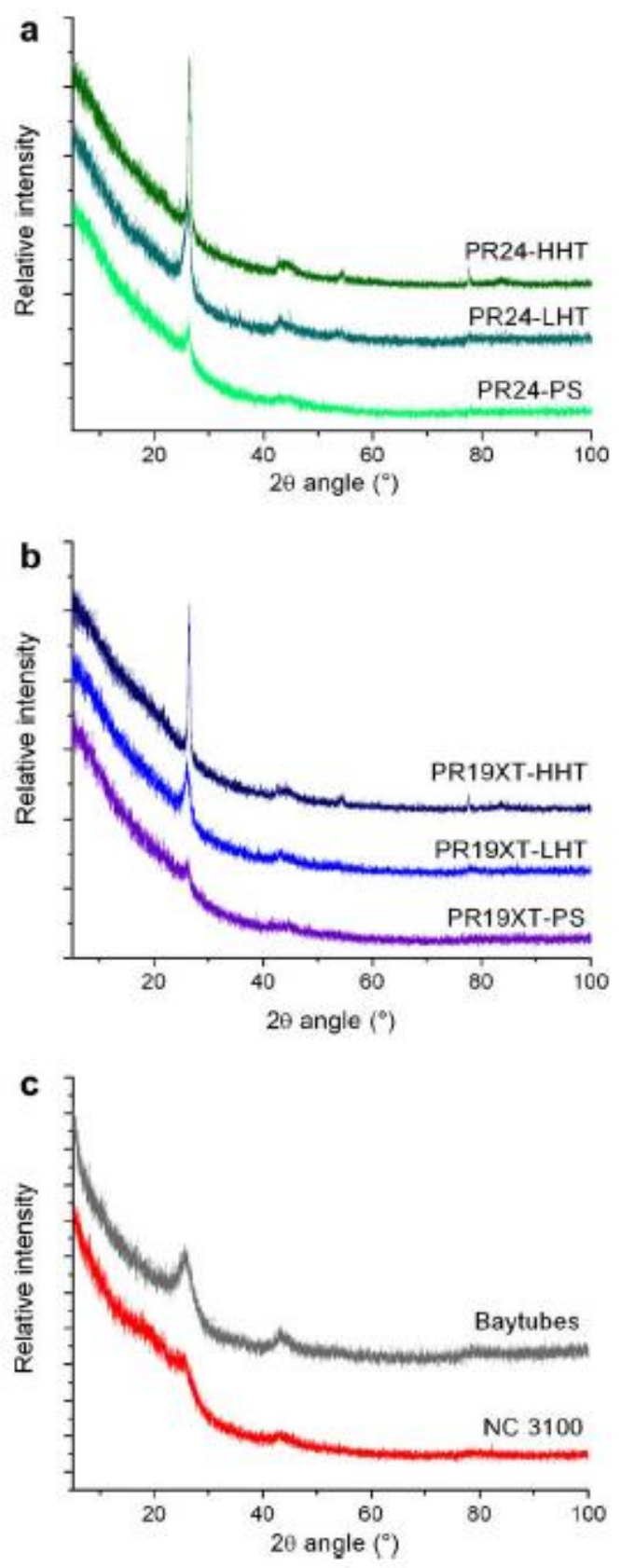

Fig. 5: XRD patterns of the Pyrograf Products PR24 series (a), PR19 series (b), Baytubes and NC 3100 samples (c).

is narrow and symmetric, which clearly indicates the formation of flat graphite-like regions. This observation can directly be linked to the SEM and TEM images of these samples (Fig. $2 \mathrm{~h}$ and Fig. 3e-f): after treatment at $3000^{\circ} \mathrm{C}$, the tubes are composed of connected flat graphite sections. Thus, one can consider that the tubular structure is destroyed and transformed into graphite.

Although Baytubes and NC 3100 nanotubes are similar in size and morphology, their XRD patterns show some differences. In particular, the peaks are narrower for the Baytubes than for the NC 3100 sample. The dominant factor for the shape and the width of the peaks is the distribution of the d spacings. HRTEM images showed that the Baytubes often present a fishbone-like structure whereas 
the Nanocyl nanotubes almost always show a typical MWCNT structure made of concentric graphene sheets. For the latter, curvature and thus strain is different for each sheet. A broader distribution of d spacings, and so broader diffraction peaks, are therefore expected.

\subsubsection{Electron Energy Loss Spectroscopy}

Core-level electron energy loss spectroscopy (EELS) provides information about the elemental composition of the sample as well as of the electronic structure, bonding state and local environment (structural order) of atoms in the probed material. EELS has been widely employed for carbon materials, especially in the case of disordered carbons for which XRD only brings little information [78].

The energy-lose near edge structure (ELNES) of core loss region of carbon consists of several distinct features. A sharp peak in the region from $282.5 \mathrm{eV}$ to $287.5 \mathrm{eV}$ corresponding to the $1 \mathrm{~s} \rightarrow \pi^{*}$ transition, and a broad feature from $287.5 \mathrm{eV}$ to $302.5 \mathrm{eV}$ containing mainly contributions from the $1 \mathrm{~s} \rightarrow \sigma^{*}$ transition $[78,79]$. EEL spectra of the Pyrograf Products VGCNFs, as well as of the Baytubes and NC 3100 MWCNTs have been compared. EEL spectra of approximately 15 different regions have been acquired and averaged for each sample. The averaged spectra are plotted in Fig. 6a-b. The EEL spectrum of a highly oriented pyrolytic graphite (HOPG) sample was added as reference. All spectra were analyzed using the Digital Micrograph software suite for background substraction (power-law model) and multiple scattering removal (Fourier-ratio method) [79].

For VGCNFs, the graphitic character significantly increases after the thermal treatments at $1500^{\circ} \mathrm{C}$ and $3000^{\circ} \mathrm{C}$ (Fig. 6a), indicated by an increase of the $\pi^{*}$ peak. The features in the region between $295 \mathrm{eV}$ and $310 \mathrm{eV}$ become more pronounced, especially for the PR24-HHT sample. These observations are consistent with SEM, TEM and XRD results. Of the two samples with the smallest tube diameters, NC 3100 and Baytubes, the latter has more welldefined $\pi^{*}$ and $\sigma^{*}$ peaks indicating a slightly higher degree of graphitization (Fig. 6b). The most prominent difference in the spectra of the NC 3100 and Baytubes samples compared to the PR series is the emergence of peaks at 303 and $306 \mathrm{eV}$ respectively. These peaks are also observed in the HOPG spectrum. Calculations by McCulloch and Brydson [80] suggest that these are due to increased ordering in the structure as they emerge only when more shells are included in the calculation. Daniels et al [78] and Batson [81] observed these features experimentally for samples treated at temperatures above $1500^{\circ} \mathrm{C}$ and for single crystal graphite respectively, indicating that they are indeed a sign of a higher degree of long-range ordering. Here, the appearance of these peaks, in particular for the PR24-HHT sample, is consistent with the large, flat, graphite-like sections observed in the HRTEM images as well as the narrow and symmetric graphite-3R (110) XRD peak at $78^{\circ}$.
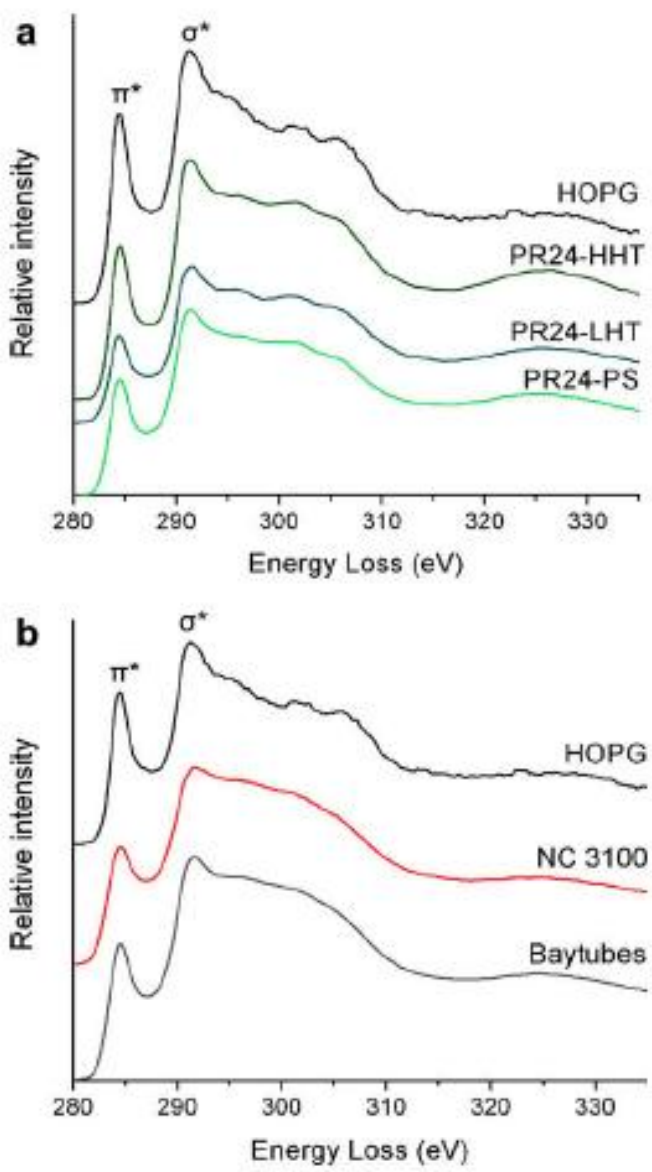

Fig. 6: (a)EEL spectra of the Pyrograf Products PR24 series samples. The EEL spectrum of HOPG has been added for comparison. (b) EEL spectra of the Baytubes and NC 3100 samples. The EEL spectrum of HOPG has been added for comparison.

\subsubsection{Raman spectroscopy}

Raman spectroscopy probes the lattice vibrations of ordered carbon materials and is therefore extremely sensitive to the graphitic character of these structures. While XRD only provides information on the structure of crystalline materials, Raman spectroscopy can also be used for molecular structures, i.e. structures with short-range order. Thus, Raman spectroscopy is widely employed for the characterization of carbon samples, and in particular for carbon nanomaterials like nanofibers, nanotubes and even Diesel soot. The origins of the Raman bands seem to be well understood [82]. It is generally accepted that the Raman spectrum of carbon nanomaterials present 3 first-order bands in the 1000-3000 $\mathrm{cm}^{-1}$ region: a D band at $\sim 1350 \mathrm{~cm}^{-1}$, a G band at $\sim 1580 \mathrm{~cm}^{-1}$ with a shoulder at $\sim 1620 \mathrm{~cm}^{-1}$ (D' band) $[83,84]$. The $\mathrm{G}$ band corresponds to the in-plane Raman vibration mode of graphite and is characteristic of the ideal graphitic lattice vibration mode, while the $\mathrm{D}$ and D' bands are attributed to lattice defects and finite graphene sheets occurring inside a CNT wall [51, 83, 84]. The first overtone of the D band (2D band) is found at $2710 \mathrm{~cm}^{-1}$. Unlike the $\mathrm{D}$ band, the 2D band follows the general selec 
Table 3. Room temperature Raman data obtained for the different nanocarbons. The fitting analysis was performed on the basis of Gaussian functions including a D' contribution around $1610 \mathrm{~cm}^{-1}$.

\begin{tabular}{|c|c|c|c|c|c|}
\hline Sample name & $\begin{array}{c}\text { D band FWHM } \\
\left(\mathrm{cm}^{-1}\right)\end{array}$ & $\begin{array}{c}\text { G band FWHM } \\
\left(\mathrm{cm}^{-1}\right)\end{array}$ & $\mathrm{I}_{\mathrm{D}} / \mathrm{I}_{\mathrm{G}}$ & $\begin{array}{l}\text { 2D band FWHM } \\
\qquad\left(\mathrm{cm}^{-1}\right)\end{array}$ & $\mathrm{I}_{2 \mathrm{D}} / \mathrm{I}_{\mathrm{G}}$ \\
\hline PR24-PS & $100^{\mathrm{a}}$ & 51 & 3.6 & 157 & 1.9 \\
\hline PR24-LHT & 77 & 56 & 1.0 & 118 & 2.0 \\
\hline PR24-HHT & - & 35 & - & 85 & 5.3 \\
\hline PR19XT-PS & $104^{\mathrm{a}}$ & 53 & 3.0 & 137 & 0.1 \\
\hline PR19XT-LHT & 62 & 49 & 1.0 & 108 & 3.0 \\
\hline PR19XT-HHT & - & 29 & - & 88 & 5.8 \\
\hline Baytubes ${ }^{\circledR}$ & 83 & 71 & 2.1 & 118 & 2.2 \\
\hline NC 3100 & 87 & 69 & 1.8 & 120 & 2.1 \\
\hline PR24LHT-2h & 77 & 51 & 1.2 & 120 & 2.1 \\
\hline PR24LHT-10h & 96 & 56 & 1.2 & 127 & 1.2 \\
\hline Baytubes-2h & 83 & 76 & 2.1 & 117 & 1.9 \\
\hline Baytubes-10h & 81 & 81 & 2.1 & 112 & 1.8 \\
\hline
\end{tabular}

${ }^{a}$ Analysis based on the band located at $\sim 1360 \mathrm{~cm}^{-1}$ superimposed on broad underlying band

tion rule. Therefore, it is always present and its intensity tends to increase with graphitization [84].

The 514 nm Raman spectra of the carbon nanomaterials after background subtraction are shown in the Supplementary Material. The spectra were analyzed using a set of Gaussian functions to describe the D, G, D' and 2D bands, respectively. The results of the peak-fitting analysis are given in Table 3. In general, the Raman spectra are characterized by a D band at $\sim 1360 \mathrm{~cm}^{-1}$, a $\mathrm{G}$ band at $\sim 1581 \mathrm{~cm}^{-1}$ with a shoulder at $\sim 1615 \mathrm{~cm}^{-1}$ (D' band) and a $2 \mathrm{D}$ band at $\sim 2710 \mathrm{~cm}^{-1}$. Systematic changes are observed when comparing samples within one series after different oxidation (PR24-LHT or Baytubes oxidized for $2 \mathrm{~h}$ and 10h) or thermal treatments (PR24 and PR19 series). The latter samples show a decrease in the width of the $D, G$ and 2D bands with increasing degree of graphitization. Delhaes et al. correlated the line width with the length of straight graphene sheets [51]. They proposed that the line width decreases when CNTs are graphitized at high temperature and that the graphene sheets are straightening out. Although measurements of the lengths of the straight sections of the graphene sheets were not possible by TEM, our observations seem to be in line with Delhaes et al.'s hypothesis (see section 3.3.3.). Similarly, the $\mathrm{D} / \mathrm{G}$ and $2 \mathrm{D} / \mathrm{G}$ intensity ratios show a dependence on thermal treatment in particular after treatment at higher temperatures. In detail, for an increasing degree of graphitization the $\mathrm{D} / \mathrm{G}$ ratio decreases while the $2 \mathrm{D} / \mathrm{G}$ ratio shows an increase. This observation is consistent with the progressive graphitization of the VGCNFs and the formation of faceted sections, i.e. formation of microcrystals. In a crystal, the D band is normally prohibited whereas the $2 \mathrm{D}$ band is allowed. When the number of defects decreases the $2 \mathrm{D}$ band is favored [82, 84 , 85].
In contrast, neither the line width nor the intensity of the $\mathrm{D}$ band were affected by the surface oxidation. This result is consistent with previous investigations on HOPG [84]. The intensity of the D band is directly linked to the number of graphene edges not to the chemical state of the edges. Consequently, we can conclude that the oxidation treatment did not increase the number of defects. In the worst case, it increased the size of the defects.

The same dependence on thermal treatment was observed for both Raman and EELS. However, few differences were observed for both techniques when comparing VGCNFs with MWCNTs as well as when comparing pristine with oxidized samples. Raman spectra show that Baytubes and NC 3100 are more graphitic than the PR24-PS sample, which contradicts the EELS results. In addition, Raman shows changes in the 2D band of oxidized samples compared to the pristine ones, while no difference can be seen in the EEL spectra. In both cases, the discrepancy between EELS and Raman results may be linked to the surface of the investigated samples. Indeed, for the PR24PS and PR19XT-PS samples, HRTEM images show a well organized core wrapped in a thick layer of highly disordered carbon (see HRTEM section), whereas MWCNT samples are homogeneous in their structure. For the oxidized samples, functionalization only takes place on the outmost walls. Nitric acid cannot diffuse though graphene sheets and so, the inner walls are not modified during the treatment. It therefore appears that Raman is more sensitive to surface modifications than EELS. 


\subsubsection{X-ray photoelectron spectroscopy}

To elucidate the degree of oxidation and graphitization XP-spectra of the $\mathrm{C} 1 \mathrm{~s}$ and $\mathrm{O} 1 \mathrm{~s}$ regions were measured. The results of the XPS C1s measurements are summarized in the Supplementary Material. Although the differences are small, a clear trend is observable: a higher degree of graphitization yields a smaller FWHM and a higher normalized area. Hence, the PR24-PS and PR19XT-PS should have the lowest degree of graphitization. Surprisingly, the XPS C1s results follow exactly the same trend as for Raman, although XPS is a surface sensitive technique whereas Raman is considered to be bulk sensitive. This observation further supports that Raman spectra of carbon nanomaterials might be more influenced by the state of the surface as one would expect. The oxidation degree of the Baytubes and PR24-LHT yield a similar trend as for graphitization: for a higher oxidation degree, the FWHM is higher and the normalized area lower. This can be understood if one assumes that the oxidation disturbs the graphitization degree. Although Raman does not show any changes in the D/G ratio, a correlation exists with the $2 \mathrm{D} / \mathrm{G}$ ratio. The $2 \mathrm{D} / \mathrm{G}$ ratio decreases with oxidation. This correlation between XPS and Raman is particularly striking for the oxidized PR24-LHT samples: both techniques show only little differences between the pristine VGCNFs and the sample treated $2 \mathrm{~h}$, while noticeable changes appear after $10 \mathrm{~h}$. To compare the oxygen functional groups on the different CNTs the O1s peak was deconvoluted in the following way: the minimum set of Gauss-Lorentz functions (FWHM: $2.2 \mathrm{eV}$ ) was used to obtain a reasonable fit. The results are summarized in the Supplementary Material. Four energetically different regions are obtained: around $530.4,532,533.4$ and $536.4 \mathrm{eV}$ respectively. While the peaks at high-binding energy are attributed to differential charging [7, 86], peaks at the low-binding energy might result from residual metal oxides. The peaks around 532 and $533.4 \mathrm{eV}$ are clearly from carbon-oxygen groups. In the pioneering work of Clark et al. [87, 88], the O1s and C1s binding energy shifts are evaluated for a range of homo polymers and organic molecules. They found mainly four groups for the $\mathrm{O} 1 \mathrm{~s}$ within a range of $\sim 2.5 \mathrm{eV}$. Following their interpretation the peaks at 532 and $533.4 \mathrm{eV}$ are related to double bonded oxygen and single bonded oxygen in acids, esters, and hydroperoxides, respectively. The shifts of the oxygen-carbon contributions in the $\mathrm{C} 1 \mathrm{~s}$ signal follow the simple rule that one oxygen-carbon bond leads to a shift of $1.5 \mathrm{eV}$ and is nearly additive. In the case of CNTs, the $\mathrm{C} 1 \mathrm{~s}$ signal consists mainly of $\mathrm{C}-\mathrm{C}$ carbon and a peak fitting with $\mathrm{C}-\mathrm{O}$ groups is ambiguous. This issue was already addressed by Proctor and Sherwood when investigating heat treated carbon fibers [89].

The changes in the C1s spectra were best analyzed by obtaining difference spectra instead of curve fitting. In this paper the difference spectra were obtained by normalizing to the minimum of the intensity between the $\mathrm{C} 1 \mathrm{~s}$ and its $\mathrm{Mg}$ satellites and subsequent subtraction. The result for the $\mathrm{HNO}_{3}$ treated PR24-LHT is shown in Fig. 7a. At least two shifted contributions at $\sim 286 \mathrm{eV}$ and $288-290 \mathrm{eV}$ could be identified corresponding to carbon atoms with one oxygen bond and two/three oxygen bonds respectively. Comparison of the oxygen related $\mathrm{C} 1 \mathrm{~s}$ signal area to the $\mathrm{O} 1 \mathrm{~s}$ signal area using atomic sensitivity factors (ASF) reveals an reasonable atomic ratio of $\mathrm{C}: \mathrm{O} \sim 1: 1$. The same ratio is obtained for the oxidized Baytubes samples.

In order to obtain additional information about the nature and especially the number of different $\mathrm{C}-\mathrm{O}$ groups in the O1s signal, high-resolution spectra were acquired at synchrotron facilities and compared with those measured in lab facilities. We have measured one sample (Nanocyl MWCNTs) at the BESSY synchrotron facility with a spectral energy resolution of $0.3 \mathrm{eV}$. Figures $7 \mathrm{~b}$ and $7 \mathrm{c}$ show a comparison of the $\mathrm{O} 1 \mathrm{~s}$ and $\mathrm{C} 1 \mathrm{~s}$ signals obtained at photon energies of 830 and $585 \mathrm{eV}$, respectively (BESSY) with a lab facility source $(\mathrm{Mg} \mathrm{K} \alpha)$. The higher spectral energy resolution leads to a $\mathrm{C} 1 \mathrm{~s}$ signal with significantly smaller FWHM while the peak characteristics remain. In contrast, the O1s signals have the same shape. This discrepancy could only be explained assuming more than 2 oxygen signals at 533.4 and $532 \mathrm{eV}$. Spectra taken at higher and lower photon energies (405 and $585 \mathrm{eV}$ for the $\mathrm{C} 1 \mathrm{~s}$ region and 650 and $830 \mathrm{eV}$ for the $\mathrm{O} 1 \mathrm{~s}$ region) are synonymous for higher and lower escape depths of electrons from the sample. A comparison of the intensities obtained at the two different photon energies reveals slightly higher oxygen content for the lower escape depth which shows that more oxygen is located on the surface (presuming homogeneously distributed carbon and oxygen).

To calculate the atomic ratio of oxygen and carbon in oxygen functionalized CNTs two simple models can be applied. The aforementioned first model assumes that $\mathrm{O}$ and $\mathrm{C}$ are homogenously distributed. Then the concentration ratio of oxygen and carbon, $\mathrm{X}_{\mathrm{O}} / \mathrm{X}_{\mathrm{C}}$ is given by:

$$
\frac{X_{O}}{X_{C}}=\frac{I_{O}}{I_{C}} \frac{I_{C, \infty}}{I_{O, \infty}}
$$

where $\mathrm{I}_{O}$ and $\mathrm{I}_{\mathrm{C}}$ are the measured intensities of oxygen and carbon and $\mathrm{I}_{\mathrm{O}, \infty}$ and $\mathrm{I}_{\mathrm{C}, \infty}$ are the intensities of the pure elements. Instead of the latter we can simply apply the atomic sensitivity factors (ASF) for both elements.

The second model assumes oxygen is mainly situated in the outermost surface area. The inner surface of the CNT will not contribute to the O1s signal due to the small inelastic mean free path (IMFP, $\lambda$ ) and hence the low escape depth of the electrons. In a rough calculation we can approximate the CNT surface with a layered model of a flat overlayer on an infinite substrate [52]. The following equations give the relative surface coverage of oxygen $\Theta_{\mathrm{O}}$ and, from this, the oxygen to carbon ratio:

$$
\Theta_{O}=\frac{\lambda_{O}\left(E_{O}\right) \cos \alpha}{a_{O}} \frac{I_{O}}{I_{C}} \frac{I_{C, \infty}}{I_{O, \infty}}=\frac{21}{1.4} \frac{I_{O}}{I_{C}} \frac{I_{C, \infty}}{I_{O, \infty}}
$$

and 


$$
\frac{X_{O}}{X_{C}}=\Theta_{O} * 0.335 /\left(r_{\text {outer }}-r_{\text {inner }}\right)
$$

where are $\lambda_{O}\left(E_{O}\right) \cos \alpha$ the attenuation length, $\mathrm{a}_{\mathrm{O}}=1.4 \AA$ twice the covalent radius of oxygen and $r_{\text {inner }}$ and $r_{\text {outer }}$ the inner and outer radius of the tubes, respectively, and finally the thickness of one layer $d_{C-C}=0.335 \mathrm{~nm}$. Fig. $7 \mathrm{~d}$ shows that the results obtained with the second model differ by a factor of 30. Therefore, it appears that the employed model is of major importance to get reliable oxygen to carbon ratios by XPS, in the case of functionalized carbon nanomaterials.

\subsubsection{Zeta potential measurements}

Nitric acid treatments are commonly used to create oxygen-containing functional groups on the surface of carbon materials. A carbon surface with acidic carboxylic groups acts as a Brønsted acid in aqueous suspensions: a proton $\left(\mathrm{H}^{+}\right)$can be released, thus leading to a negatively charged surface. These surface functional groups play a dramatic role when the carbon material is used as adsorbent (gas or ions), catalyst support or polymer reinforcement agent $[11,90]$. Several reviews on their characterization and quantification appeared in the literature $[8,9,11,12$, 91]. Among the different techniques available, electrokinetics measurements are often carried out because they provide at the same time information about the chemical state of the surface, i.e. the predominance of acid or basic groups, and about the surface charge as a function of the $\mathrm{pH}$. The isoelectric point (IEP), where the electrokinetic potential or Zeta potential is zero, indicates at which $\mathrm{pH}$ the surface possesses as many positive as negative charges. For classical catalyst supports like silica or alumina, the IEP is typically at $\mathrm{pH}=2$ and $\mathrm{pH}=9$, respectively. The Zeta potential is particularly important in catalysis as it strongly influences the adsorption of transition metal ions during the impregnation of the catalyst support, and consequently the dispersion of the metallic active phase. In the present case, the Zeta potential measurements also provide useful information about the nature of the oxygen functional group located on the surface of the carbon nanomaterials. For example, carboxylic acid and anhydride are strongly acidic whereas lactones and phenolic groups only possess a very weak acidity. Strongly acidic groups tend to be deprotonated and thus negatively charged whereas weakly acidic or basic groups tend to be protonated, thus leading to positive charges on the surface.

Zeta potential (ZP) measurements (Fig. 8) show that the oxidized VGCNF (PR24-LHT) and MWCNT (Baytubes) possess a negative $\mathrm{ZP}$ for $\mathrm{pH}$ values higher than 4 . The $\mathrm{ZP}$ values remain all lower for the Baytubes- $2 \mathrm{~h}$ sample than for the PR24LHT-2h sample. The surface of the Baytubes- $2 \mathrm{~h}$ sample is consequently more acidic than in the case of the PR24LHT-2h. Raman and XPS revealed that pristine Baytubes are less graphitized, and consequently feature more defects, that the PR24-LHT VGCNFs. It therefore appears that oxidation mainly takes place on existing defects. Extending the duration of the acid treatments from 2 to $10 \mathrm{~h}$, leads to a deeper oxidation of the surface. Consequently, the $\mathrm{ZP}$ remains negative even at $\mathrm{pH}=1.5$. Other groups already reported similar observation for activated carbon and other multiwall carbon nanotubes samples treated in a similar way [92-95]. Surprisingly, the Baytubes-10h sample presents a positive $\mathrm{ZP}$ at low $\mathrm{pH}$, although XPS confirms that it contains more oxygen on its surface than the Baytubes-2h sample. In this case, it appears that a part of the acidic functional groups can be lost if the oxidation treatment is pursued for $10 \mathrm{~h}$.

\subsubsection{Temperature programmed oxidation}

The behavior of the CNTs under oxidizing conditions was evaluated by temperature programmed oxidation (TPO) and thermogravimetry (TG). The measurement conditions, e.g. the sample mass or the temperature ramp, can lead to peak shifts and peak broadening (Fig. 9) [96, 97]. The optimal conditions for TPO appeared to be $3 \mathrm{mg}$ of sample mass and a $2{ }^{\circ} \mathrm{C} / \mathrm{min}$ ramp. Therefore, all the measurements were performed under these conditions. The combustion temperatures, i.e. the temperature of the half weight loss in the TG curve, are summarized in Table 4. The oxidation of carbon materials is a complicated process divided into several steps [7]. The nature and the density of defects per surface area as well as per weight unit play a crucial role in the temperature and kinetics of the burning process in a TPO/TG experiment. Therefore, the interpretation of the results is not straightforward. The PR19 series generally exhibit higher combustion temperatures compared to the PR24, while EELS, Raman and XPS show that both products exhibit the same graphitization. In this case, the differences can be explained by the lower surface area of the PR19 products. Differences between the different grades within one series are more pronounced between PS and LHT grades than between LHT and HHT. Although it is reported that carbon graphitizes at ca. $2000^{\circ} \mathrm{C}$, it appears that the order already improves significantly at $1500^{\circ} \mathrm{C}$. This trend is consistent with the evolution of the graphitic character observed by TEM, EELS, Raman and XPS. Oxidation of the PR24-LHT sample with nitric acid for $2 \mathrm{~h}$ does not lead to any significant change in the combustion temperature compared to the pristine sample. EELS, Raman and XPS measurements confirm that the structure of the VGCNF has not been affected by this treatment, although the oxygen concentration on the surface rises from 12 to 29 at.\%. Therefore, it appears that oxidation mainly takes place on the edges of the surface graphene sheets. Oxidation for longer time, i.e. $10 \mathrm{~h}$, appears to have a stronger impact on the stability of the carbon structure, as observed by Raman and XPS C1s. The combustion temperature decreases by $50^{\circ} \mathrm{C}$. Interestingly, for Raman, only $\mathrm{I}_{2 \mathrm{D}} / \mathrm{I}_{\mathrm{G}}$ ratio changes significantly, decreasing from ca. 2.0 for PR24-LHT and PR24-LHT oxidized $2 \mathrm{~h}$ to 1.2 for the sample oxidized for $10 \mathrm{~h}$. Whereas the $\mathrm{D}$ band in the $\mathrm{Ra}$ 

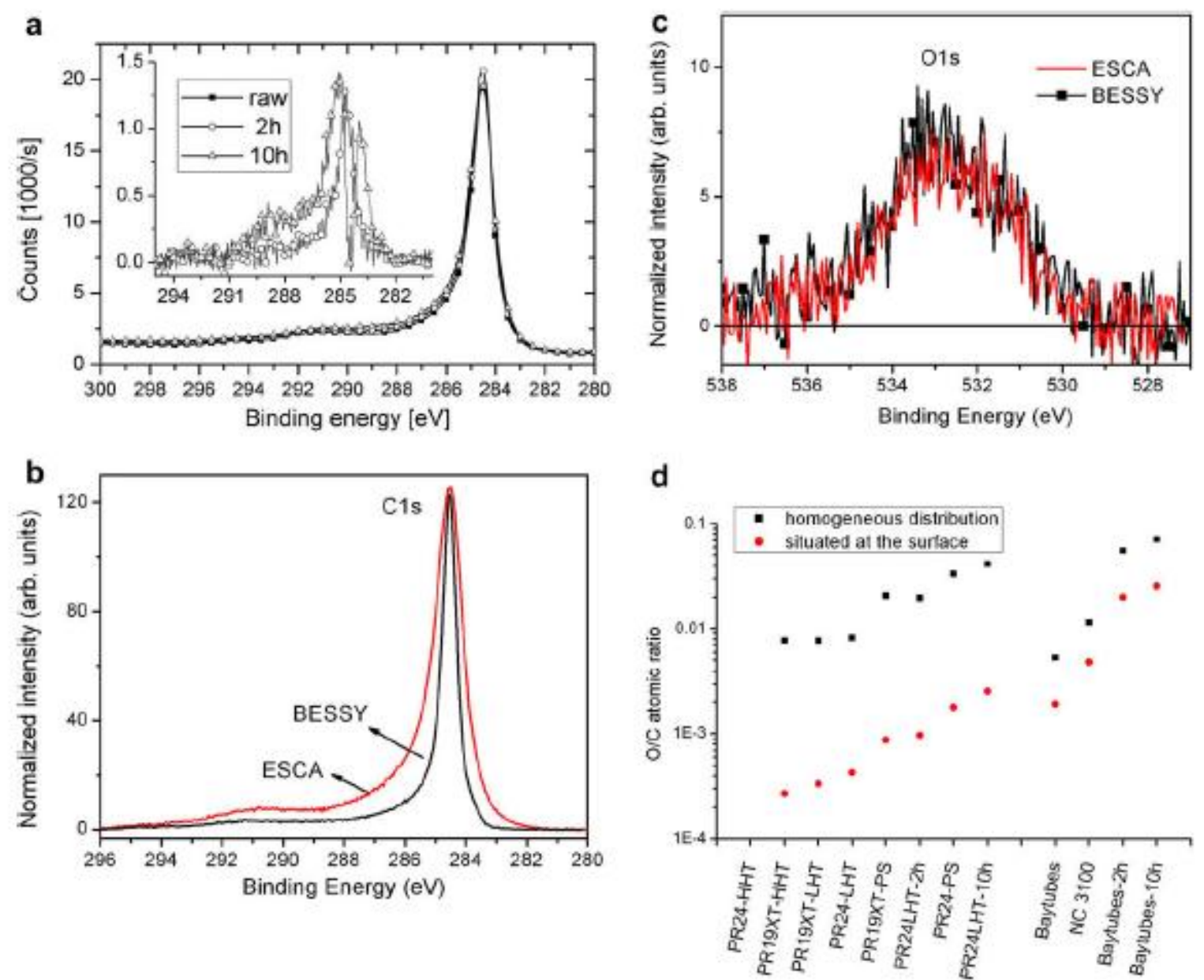

Fig. 7: (a) C1s region XP-spectra of PR24-LHT, PR24LHT-2h and PR24LHT-10h. Inset: difference spectra of raw and oxidized samples. (b) C1s XP-spectra of the Nanocyl MWCNTs measured in an ESCA setup and at the BESSY synchrotron facility. (c) O1s XP-spectra of the Nanocyl MWCNTs measured in an ESCA setup and at the BESSY synchrotron facility.(d) XPS atomic ratios of oxygen to carbon assuming a) homogeneous distribution and b) oxygen situated on the topmost layer.

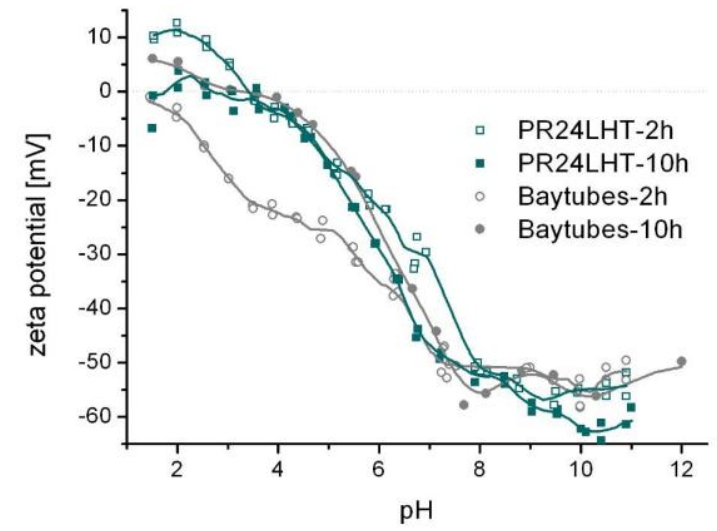

Fig. 8: Zeta potential measurements obtained for the PR24-LHT (square) and Baytubes (round) samples treated with nitric acid for $2 \mathrm{~h}$ (opened symbols) and $10 \mathrm{~h}$ (closed symbols). man spectrum originates from the edges of the graphene sheets, the 2D band seems to be linked to structural defects existing within the graphene sheets, i.e. its intensity increases when the structure of the sheet approaches the ideal structure existing in graphite [51, 84]. This also explains why a correlation was found between the intensity of 2D band and the intensity of the C1s peak in XPS (see XPS section). At that stage, it is not clear how the structure of the graphene sheet is modified when extending the duration of the oxidizing treatment. However, TPO results show that new defects are created that lower the stability of the VGCNF towards combustion.

Combustion of the Baytubes and NC 3100 MWCNTs take place at lower temperatures than for VGCNFs, most probably because their specific surface area is much higher, i.e. ca. $300 \mathrm{~m}^{2} / \mathrm{g}$ instead of $20 \mathrm{~m}^{2} / \mathrm{g}$, and their graphitic character is lower, as observed from EELS measurements. It is also worth noting that pristine Baytubes present a combustion temperature $95^{\circ} \mathrm{C}$ lower than NC 3100 MWCNTs, despite the fact that the carbon nanotubes of the two samples have a similar size, surface area and graphitic 


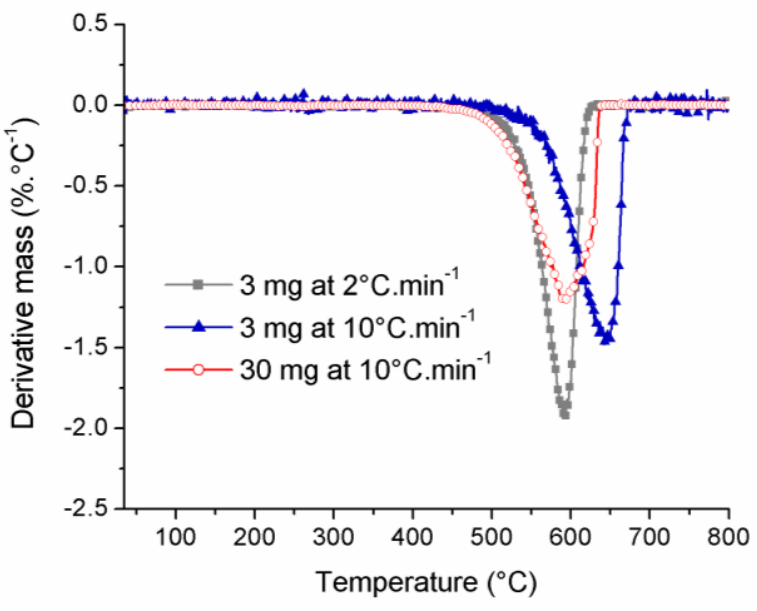

Fig. 9: First derivatives of the thermogravimetric curves obtained for the Nanocyl sample measured in different conditions.

character, determined from EELS, XPS and Raman data. The relatively high amount of catalyst present in the Baytubes compared to other samples might play some role in this low combustion temperature. The ashes remaining in the crucible after TPO represented 4 wt.\% of the initial mass in the case of the pristine Baytubes. For all other samples, the amount of ashes ranged between 0.1 and 1 wt. $\%$. The catalyst present in the Baytubes dropped below $0.5 \mathrm{wt} . \%$ after the treatment with nitric acid for $2 \mathrm{~h}$ and 10 h. However, for these two samples the combustion temperature is still lower than for the NC 3100 MWCNTs. Thus, the amorphous carbon observed by HRTEM on the outer surface of the pristine and of the oxidized Baytubes probably also plays some role: this carbon burns at lower temperature and creates a hot spot that initiates the combustion of the sample.

\section{Conclusion}

The extensive investigation of commercial carbon nanostructures commonly employed as carbon nanotubes has shown that only few materials can be described as real MWCNTs, i.e. formed by coaxial singlewall carbon nanotubes. Although Pyrograf Products PR19 and PR24 exhibit a tubular structure, they undoubtedly consist of a catalytically grown hollow fishbone fiber core wrapped with pyrolitically grown carbon. SEM and HRTEM investigations showed that products from Bayer MaterialScience and Nanocyl appeared to be more homogeneous in size and morphology, and exhibited only little amorphous carbon and debris on their surface. The majority of the tubes in the NC 3100 sample had well-aligned walls, parallel to the main axis, thus being relatively close to the perfect MWCNT structure. In contrast, Baytubes presented many structural defects leading to tube wall terminations.

The graphitic character, and reciprocally the number of structural defects, has been investigated using XRD,
Table 4. Temperature programmed oxidation (TPO) results: temperature of $50 \%$ mass loss.

\begin{tabular}{cc}
\hline Sample name & $\mathrm{T}_{50 \%}\left({ }^{\circ} \mathrm{C}\right)$ \\
\hline PR24-PS & 548 \\
PR24-LHT & 699 \\
PR24-HHT & 718 \\
PR19XT-PS & 565 \\
PR19XT-LHT & 704 \\
PR19XT-HHT & 735 \\
Baytubes ${ }^{\circledR}$ & 479 \\
NC 3100 & 574 \\
PR24LHT-2h & 695 \\
PR24LHT-10h & 649 \\
Baytubes-2h & 492 \\
Baytubes-10h & 502
\end{tabular}

TEM, EELS, Raman and XPS. Although XRD patterns are often shown in publications dealing with carbon nanotubes synthesis and applications, we found that this technique is not reliable in the case of narrow MWCNTs. Curvature and strain lead to a distribution of $d$ spacings and consequently to broad peaks, independently of the graphitic character of the investigated sample. Correlations with other structuresensitive techniques were hardly found. Diffraction peaks characteristic of graphite actually originated either from carbon impurities or from a partial destruction of the tubular nanomaterial, as imaged by HRTEM. The EELS, Raman and XPS measurements were well-correlated with TEM observations. A close link between EELS and Raman results was expected as both techniques are bulk sensitive. In addition, Raman is commonly used to characterize the structural order in carbon nanotubes, i.e. their graphitic character. Surprisingly, a closer correlation was found between Raman and XPS, although XPS is surface sensitive. It appeared that Raman spectra contain much more information from the surface as expected from previous investigations. The intensity and the width of the XPS C1s peak were influenced by any modification in the carbon structure, from graphitization as well as from oxidation. The $\mathrm{I}_{\mathrm{D}} / \mathrm{I}_{\mathrm{G}}$ ratio calculated from Raman spectra is linked to the density of edges in the sample. Edges are either due to terminations in the graphene sheets or to large structural defects like holes. Thus, the $I_{D} / I_{G}$ ratio varies with the graphitization but it is hardly influenced by other modifications, like for example by chemical functionalization, as long as these modifications do not create new edges. In the present work, oxidation with nitric acid did not lead to any change in the $I_{D} / I_{G}$ ratio, although XPS confirmed that significant amounts of oxygen were introduced on the surface. Against all expectations, nitric acid did not create additional edges but only oxidized existing ones. In contrast to the $\mathrm{I}_{\mathrm{D}} / \mathrm{I}_{\mathrm{G}}$ ratio, the $\mathrm{I}_{2 \mathrm{D}} / \mathrm{I}_{\mathrm{G}}$ ratio appeared to be sensitive to any perturbation in the carbon backbone, structural (defects) as well as chemical (oxidation state). A strong correlation was 
found between the intensity of the $2 \mathrm{D}$ band and the XPS $\mathrm{C} 1 \mathrm{~s}$ peak. Unfortunately, the interpretation of the 2D band is not straightforward yet. Therefore, a deeper interpretation of these results and their correlation with XPS and HRTEM is not possible at present.

The effect of structural defects on the physicochemical properties of the carbon nanostructures was investigated using oxidation with nitric acid or with air as probe reactions. ZP measurements as well as XPS (O1s and C1s) and Raman spectra further confirmed that oxidation and, consequently, the formation of oxygen-containing functional groups, takes mainly place on existing structural defects. The amount of oxygen introduced on the surface is a function of the density of defects in the pristine carbon material. TPO is often used in the literature to probe the quality of carbon nanotubes samples, i.e. the amount of amorphous carbon in the sample as well as the average graphitic character of the nanotubes. In the present work, oxidation temperatures followed the expected trend in the

\section{References}

[1] Hofmann U, Lemcke W. Kristallstruktur und Katalytische Wirksamkeit von Kohlenstoff. Z Anorg Allg Chem. 1932;208(2):194-212.

[2] Dresselhaus MS, Dresselhaus G, Sugihara K, Spain IL, Goldberg HA. Graphite fibers and filaments. Berlin / Heidelberg: Springer 1988.

[3] McEnaney B. Properties of Activated Carbons. In: Schüth F, Sing KSW, Weitkamp J, eds. Handbook of Porous Solids. Weinheim: Wiley-VCH Verlag 2002:1828-63.

[4] Patrick JW, Hanson S. Pore Structure of Graphite, Coke and Composites. In: Schüth F, Sing KSW, Weitkamp J, eds. Handbook of Porous Solids. Weinheim: Wiley-VCH Verlag 2002:1900-22.

[5] Rodriguez-Reinoso F. Production and Applications of Activated Carbons. In: Schüth F, Sing KSW, Weitkamp J, eds. Handbook of Porous Solids. Weinheim: Wiley-VCH Verlag 2002:1766-827.

[6] Schlögl R. Surface Composition and Structure of Active Carbons. In: Schüth F, Sing KSW, Weitkamp J, eds. Handbook of Porous Solids. Weinheim: Wiley-VCH Verlag 2002:1863-900.

[7] Schlögl R. Carbons. In: Ertl G, Knözinger H, Schüth F, Weitkamp J, eds. Handbook of Heterogeneous Catalysis. Weinheim: Wiley VCH Verlag 2007.

[8] Boehm HP, Diehl E, Heck W, Sappok R. Surface Oxides of Carbon. Angew Chem, Int Ed Engl. 1964;3(10):669-77.

[9] Boehm HP. Some aspects of the surface chemistry of carbon blacks and other carbons. Carbon. 1994;32(5):759-69.

[10] Boehm HP. The first observation of carbon nanotubes. Carbon. 1997;35(4):581-4.

[11] Boehm HP. Carbon Surface Chemistry. In: Delhaes P, ed. Graphite and Precursors. Amsterdam: Gordon and Breach Science Publishers 2001.

[12] Boehm HP. Surface oxides on carbon and their analysis: a critical assessment. Carbon. 2002;40(2):145-9.

[13] Monthioux M, Kuznetsov VL. Who should be given the credit for the discovery of carbon nanotubes? Carbon. 2006;44(9):1621-3.

[14] Iijima S. Helical microtubules of graphitic carbon. Nature. 1991;354(6348):56-8. case of the VGCNFs: the combustion temperature increased with the thermal treatment. However, TPO results were also strongly influenced by the specific surface area of the samples as well as by remaining catalyst impurities or carbon debris on the surface. Clearly, a correlation between the combustion temperature and structural features obtained from TEM, EELS, Raman or XPS was not found.

So far, correlations between the properties of carbon nanotube-based materials and the structure of the employed CNTs have not been established in the literature, mainly because no reference CNT samples have been available. The availability of several commercial products, e.g. Baytubes or NC 3100 , and the characterizations provided in this work should facilitate such correlations and hopefully help choose the right type of CNT for a specific application, as well as help to better understand and design new CNT-based materials with the desired properties.

[15] Kang I, Heung YY, Kim JH, Lee JW, Gollapudi R, Subramaniam $\mathrm{S}$, et al. Introduction to carbon nanotube and nanofiber smart materials. Compos Part B-Eng. 2006;37(6):382-94.

[16] Gogotsi Y. Carbon nanomaterials. Boca Raton: Taylor \& Francis 2006

[17] Nhut J-M, Nguyen P, Pham-Huu C, Keller N, Ledoux M-J. Carbon nanotubes as nanosized reactor for the selective oxidation of H2S into elemental sulfur. Catal Today. 2004;9192:91-7.

[18] Pan X, Fan Z, Chen W, Ding Y, Luo H, Bao X. Enhanced ethanol production inside carbon-nanotube reactors containing catalytic particles. Nat Mater. 2007;6(7):507-11.

[19] Prato M, Kostarelos K, Bianco A. Functionalized Carbon Nanotubes in Drug Design and Discovery. Acc Chem Res. 2008;41:60-8.

[20] Dai H. Nanotube Growth and Characterization. In: Dresselhaus MS, Dresselhaus G, Avouris P, eds. Carbon Nanotubes: Synthesis, Structure, Properties and Application. Berlin / Heidelberg: Springer 2001:29-53.

[21] Ajayan PM, Zhou OZ. Applications of Carbon Nanotubes. In: Dresselhaus MS, Dresselhaus G, Avouris P, eds. Carbon Nanotubes: Synthesis, Structure, Properties and Application. Berlin / Heidelberg: Springer 2001:391-425.

[22] Andrews R, Jacques D, Qian D, Rantell T. Multiwall Carbon Nanotubes: Synthesis and Application. Acc Chem Res. 2002;35(12):1008-17.

[23] Dai H. Carbon Nanotubes: Synthesis, Integration, and Properties. Acc Chem Res. 2002;35(12):1035-44.

[24] Zhou O, Shimoda H, Gao B, Oh S, Fleming L, Yue G. Materials Science of Carbon Nanotubes: Fabrication, Integration, and Properties of Macroscopic Structures of Carbon Nanotubes. Acc Chem Res. 2002;35(12):1045-53.

[25] Popov VN. Carbon nanotubes: properties and application. Mater Sci Eng, R. 2004;43(3):61-102.

[26] Understanding Carbon Nanotubes: fron Basics to Applications. Berlin/Heidelberg: Springer 2006.

[27] Paradise M, Goswami T. Carbon nanotubes - Production and industrial applications. Materials \& Design. 2007;28(5):1477-89. 
[28] Yakobson BI, Avouris P. Mechanical Properties of Carbon Nanotubes. In: Dresselhaus MS, Dresselhaus G, Avouris P, eds. Carbon Nanotubes: Synthesis, Structure, Properties and Application. Berlin / Heidelberg: Springer 2001:287-327.

[29] Miyagawa H, Misra M, Mohanty AK. Mechanical Properties of Carbon Nanotubes and Their Polymer Nanocomposites. J Nanosci Nanotechnol. 2005;5:1593-615.

[30] Coleman JN, Khan U, Gun'ko YK. Mechanical Reinforcement of Polymers Using Carbon Nanotubes. Advanced Materials. 2006;18(6):689-706.

[31] Koziol K, Vilatela J, Moisala A, Motta M, Cunniff P, Sennett $\mathrm{M}$, et al. High-Performance Carbon Nanotube Fiber. Science. 2007 November 15, 2007;318(5858):1892-5.

[32] Baibarac M, Gómez-Romero P. Nanocomposites Based on Conducting Polymers and Carbon Nanotubes: From Fancy Materials to Functional Applications. J Nanosci Nanotechnol. 2006;6(2):289-302.

[33] Markarian J. Automotive and packaging offer growth opportunities for nanocomposites. Plastics, Additives and Compounding. 2005;7(6):18-21.

[34] Thayer AM. Carbon nanotubes by the metric ton. Chem Eng News. 2007;85(46):29-35.

[35] Tibbetts GG, Lake ML, Strong KL, Rice BP. A review of the fabrication and properties of vapor-grown carbon nanofiber/polymer composites. Compos Sci Technol. 2007;67(78):1709-18.

[36] Graham Andrew P, Duesberg Georg S, Seidel Robert V, Liebau M, Unger E, Pamler W, et al. Carbon Nanotubes for Microelectronics? Small. 2005;1(4):382-90.

[37] Rodríguez-reinoso F. The role of carbon materials in heterogeneous catalysis. Carbon. 1998;36(3):159-75.

[38] Serp P, Corrias M, Kalck P. Carbon nanotubes and nanofibers in catalysis. Appl Catal, A. 2003;253(2):337-58.

[39] Lin Y, Taylor S, Li H, Fernando KAS, Qu L, Wang W, et al. Advances toward bioapplications of carbon nanotubes. J Mater Chem. 2004;14(4):527-41.

[40] Forró L, Schönenberger C. Physical Properties of Multi-wall Nanotubes. In: Dresselhaus MS, Dresselhaus G, Avouris P, eds. Carbon Nanotubes: Synthesis, Structure, Properties and Application. Berlin / Heidelberg: Springer 2001:329-91.

[41] Wildgoose GG, Banks CE, Compton RG. Metal Nanoparticles and Related Materials Supported on Carbon Nanotubes: Methods and Applications. Small. 2006;2(2):182-93.

[42] Tasis D, Tagmatarchis N, Bianco A, Prato M. Chemistry of Carbon Nanotubes. Chem Rev. 2006;106(3):1105-36.

[43] Pisanic Ii TR, Blackwell JD, Shubayev VI, Finones RR, Jin S. Nanotoxicity of iron oxide nanoparticle internalization in growing neurons. Biomaterials. 2007;28(16):2572-81.

[44] Sayes CM, Liang F, Hudson JL, Mendez J, Guo W, Beach $\mathrm{JM}$, et al. Functionalization density dependence of singlewalled carbon nanotubes cytotoxicity in vitro. Toxicol Lett. 2006;161(2):135-42.

[45] Singh R, Pantarotto D, Lacerda L, Pastorin G, Klumpp C, Prato $\mathrm{M}$, et al. Tissue biodistribution and blood clearance rates of intravenously administered carbon nanotube radiotracers. Proc Natl Acad Sci U S A. 2006 February 28, 2006;103(9):3357-62.

[46] Smart SK, Cassady AI, Lu GQ, Martin DJ. The biocompatibility of carbon nanotubes. Carbon. 2006;44(6):1034-47.

[47] Yu Z, Chen D, Totdal B, Holmen A. Effect of catalyst preparation on the carbon nanotube growth rate. Catal Today. 2005;100(3-4):261-7.

[48] Zhou J-H, Sui Z-J, Li P, Chen D, Dai Y-C, Yuan W-K. Structural characterization of carbon nanofibers formed from different carbon-containing gases. Carbon. 2006;44(15):3255-62.
[49] Grobert N. Nanotubes - grow or go? Materials Today. 2006;9(10):64-.

[50] Arkema inaugurates carbon nanotube pilot plant; other CNT developments. Additives for Polymers. 2006;2006(3):6-7.

[51] Delhaes P, Couzi M, Trinquecoste M, Dentzer J, Hamidou H, Vix-Guterl C. A comparison between Raman spectroscopy and surface characterizations of multiwall carbon nanotubes. Carbon. 2006;44(14):3005-13.

[52] Briggs D, Seah MP. Practical Surface Analysis. Chichester: Wiley 1990.

[53] Tanuma S, Powell CJ, Penn DR. Calculations of electron inelastic mean free paths. II. Data for 27 elements over the 50-2000 eV range. Surf Interface Anal. 1991;17(13):911-26.

[54] Lavin GJ, Subramoney S, Ruoff RS, Berber S, Tomanek D. Scrolls and nested tubes in multiwall carbon nanotubes. Carbon. 2002;40(7):1123-30.

[55] Bacon R. Growth, Structure, and Properties of Graphite Whiskers. J Appl Phys. 1960;31(2):283-90.

[56] Park C, Rodriguez NM, Baker RTK. Carbon Deposition on Iron-Nickel during Interaction with Carbon MonoxideHydrogen Mixtures. J Catal. 1997;169(1):212-27.

[57] Dresselhaus MS, Endo M. Relation of Carbon Nanotubes to Other Carbon Materials. In: Dresselhaus MS, Dresselhaus G, Avouris P, eds. Carbon Nanotubes: Synthesis, Structure, Properties and Application. Berlin / Heidelberg: Springer 2001:11-28.

[58] Allouche H, Monthioux M. Chemical vapor deposition of pyrolytic carbon on carbon nanotubes. Part 2. Texture and structure. Carbon. 2005;43(6):1265-78.

[59] Allouche H, Monthioux M, Jacobsen RL. Chemical vapor deposition of pyrolytic carbon on carbon nanotubes: Part 1. Synthesis and morphology. Carbon. 2003;41(15):2897-912.

[60] Monthioux M, Allouche H, Jacobsen RL. Chemical vapour deposition of pyrolytic carbon on carbon nanotubes: Part 3: Growth mechanisms. Carbon. 2006;44(15):3183-94.

[61] Lakshminarayanan PV, Toghiani H, Pittman CU. Nitric acid oxidation of vapor grown carbon nanofibers. Carbon. 2004;42(12-13):2433-42.

[62] Shi D, Lian J, He P, Wang LM, van Ooij WJ, Schulz M, et al. Plasma deposition of Ultrathin polymer films on carbon nanotubes. Appl Phys Lett. 2002;81(27):5216-8.

[63] Su DS, Maksimova N, Delgado JJ, Keller N, Mestl G, Ledoux MJ, et al. Nanocarbons in selective oxidative dehydrogenation reaction. Catal Today. 2005;102-103:110-4.

[64] Svrcek V, Pham-Huu C, Amadou J, Begin D, Ledoux MJ, Normand FL, et al. Filling and capping multiwall carbon nanotubes with silicon nanocrystals dispersed in $\mathrm{SiO}$ [sub 2]based spin on glass. J Appl Phys. 2006;99(6):064306-9.

[65] Xia W, Wang Y, Bergstraer R, Kundu S, Muhler M. Surface characterization of oxygen-functionalized multi-walled carbon nanotubes by high-resolution X-ray photoelectron spectroscopy and temperature-programmed desorption. Appl Surf Sci. 2007;254(1):247-50.

[66] Liegeois F, Vandecasserie C, inventors; Nanocyl SA, assignee. Method for producing carbon nanotubes. Belgium patent WO2006135991. 2006.

[67] Prada Silvy R, Culot B, Pirlot C, inventors; Nanocyl SA, assignee. Catalyst system for a multi-walled carbon nanotube production process. Belgium patent WO2007033438. 2007.

[68] Prada Silvy R, Liegeois F, Culot B, Lambert S, inventors; Nanocyl SA, assignee. Method of synthesising a support catalyst for the production of carbon nanotubes. Belgium patent WO2006079186. 2006.

[69] Buchholz S, Duff DG, Michele V, Mleczko L, Münnich C, Rudolf R, et al., inventors; Bayer Technology Services $\mathrm{GmbH}$, assignee. Catalyst for producing carbon nanotubes by 
means of the decomposition of gaseous carbon compounds on a heterogeneous catalyst. Germany patent WO2006050903. 2006.

[70] Buchholz S, Michele V, Mleczko L, Münnich C, Rudolf R, Wolf A, inventors; Bayer Materialscience AG, assignee. Process for continuously preparing catalysts. Germany patent WO2007093337. 2007.

[71] Madroñero A, Verdú M, Froyen L, Domínguez M. A Diffusion Model for Sword in Sheath Failure Mode in Vapour Grown Carbon Fibers. Adv Perform Mater. 1997;4(3):30515.

[72] Ugarte D. Morphology and structure of graphitic soot particles generated in arc-discharge C60 production. Chem Phys Lett. 1992;198(6):596-602.

[73] Oberlin A. Carbonization and graphitization. Carbon. 1984;22(6):521-41.

[74] Peigney A, Laurent C, Flahaut E, Bacsa RR, Rousset A. Specific surface area of carbon nanotubes and bundles of carbon nanotubes. Carbon. 2001;39(4):507-14.

[75] Warren BE. X-Ray Diffraction in Random Layer Lattices. Phys Rev. 1941;59(9):693.

[76] Kercher AK, Nagle DC. Microstructural evolution during charcoal carbonization by X-ray diffraction analysis. Carbon. 2003;41(1):15-27.

[77] Li ZQ, Lu CJ, Xia ZP, Zhou Y, Luo Z. X-ray diffraction patterns of graphite and turbostratic carbon. Carbon. 2007;45(8):1686-95.

[78] Daniels H, Brydson R, Rand B, Brown A. Investigating carbonization and graphitization using electron energy loss spectroscopy (EELS) in the transmission electron microscope (TEM). Philos Mag. 2007;87(27):4073 - 92.

[79] Egerton RF. Electron Energy-Loss Spectroscopy in the Electron Microscope. New-York: Plenum Press 1989.

[80] McCulloch DG, Brydson R. Carbon K-shell near-edge structure calculations for graphite using the multiple-scattering approach. J Phys: Condens Matter. 1996;8(21):3835-41.

[81] Batson PE. Carbon 1s near-edge-absorption fine structure in graphite. Phys Rev B. 1993;48(4):2608.

[82] Reich S, Thomsen C, Maultzsch J. Carbon Nanotubes. Weinheim: WILEY-VCH Verlag 2004.

[83] Tuinstra F, Koenig JL. Raman Spectrum of Graphite. J Chem Phys. 1970;53(3):1126-30.

[84] Wang Y, Alsmeyer DC, McCreery RL. Raman spectroscopy of carbon materials: structural basis of observed spectra. Chem Mater. 1990;2(5):557-63.

[85] Dresselhaus MS, Eklund PC. Phonons in carbon nanotubes. Adv Phys. 2000;49(6):705 - 814.
[86] Rodriguez NM, Anderson PE, Wootsch A, Wild U, Schlögl R, Paál Z. XPS, EM, and Catalytic Studies of the Accumulation of Carbon on Pt Black. J Catal. 2001;197(2):365-77.

[87] Clark DT, Cromarty BJ, Dilks A. A theoretical investigation of molecular core binding and relaxation energies in a series of oxygen-containing organic molecules of interest in the study of surface oxidation of polymers. J Polym Sci, Part A: Polym Chem. 1978;16(12):3173-84.

[88] Clark DT, Thomas HR. Applications of ESCA to polymer chemistry. XVII. Systematic investigation of the core levels of simple homopolymers. J Polym Sci, Part A: Polym Chem. 1978;16(4):791-820.

[89] Proctor A, Sherwood PMA. X-ray photoelectron spectroscopic studies of carbon fibre surfaces. I. carbon fibre spectra and the effects of heat treatment. J Electron Spectrosc Relat Phenom. 1982;27(1):39-56.

[90] Zielke U, Hüttinger KJ, Hoffman WP. Surface-oxidized carbon fibers: I. Surface structure and chemistry. Carbon. 1996;34(8):983-98.

[91] Leon y Leon CA, Radovic LR. Interfacial Chemistry and Electrochemistry of Carbon Surfaces. In: Thrower PA, ed. Chemistry and Physics of Carbon. New-York: Marcel Dekker 1994.

[92] Noh JS, Schwarz JA. Effect of $\mathrm{HNO}_{3}$ treatment on the surface acidity of activated carbons. Carbon. 1990;28(5):675-82.

[93] Radovic LR, Rodriguez-Reinoso F. Carbon Materials in Catalysis. In: Thrower PA, ed. Chemistry and Physics of Carbon. New-York: Marcel Dekker 1997.

[94] Li Y-H, Wang S, Luan Z, Ding J, Xu C, Wu D. Adsorption of cadmium(II) from aqueous solution by surface oxidized carbon nanotubes. Carbon. 2003;41(5):1057-62.

[95] Liu Y, Gao L. A study of the electrical properties of carbon nanotube- $\mathrm{NiFe}_{2} \mathrm{O}_{4}$ composites: Effect of the surface treatment of the carbon nanotubes. Carbon. 2005;43(1):47-52.

[96] Li C, Minh CL, Brown TC. Kinetics of $\mathrm{CO}$ and $\mathrm{CO}_{2}$ Evolution During the Temperature-Programmed Oxidation of Coke Deposited on Cracking Catalysts. J Catal. 1998;178(1):27583.

[97] McKee GSB, Vecchio KS. Thermogravimetric Analysis of Synthesis Variation Effects on CVD Generated Multiwalled Carbon Nanotubes. J Phys Chem B. 2006;110(3):1179-86. 